Research Article

\title{
Experimental Study on Shear Resistance of Carex-Root-Fibered Soil
}

\author{
Feng-Chi Wang $\mathbb{D},{ }^{1}$ Ming-Ze Zhao $\mathbb{D}^{2},{ }^{2}$ and Qi Sun $\mathbb{D D}^{2}$ \\ ${ }^{1}$ School of Transportation Engineering, Shenyang Jianzhu University, Shenyang 110168, China \\ ${ }^{2}$ School of Civil Engineering, Shenyang Jianzhu University, Shenyang 110168, China \\ Correspondence should be addressed to Feng-Chi Wang; cefcwang@sjzu.edu.cn
}

Received 22 December 2020; Revised 25 July 2021; Accepted 13 August 2021; Published 31 August 2021

Academic Editor: Junhui Zhang

Copyright (C) 2021 Feng-Chi Wang et al. This is an open access article distributed under the Creative Commons Attribution License, which permits unrestricted use, distribution, and reproduction in any medium, provided the original work is properly cited.

\begin{abstract}
Carex shows strong vitality, adaptability, and performance with regard to soil consolidation and slope protection but is often disregarded as a weed. This study proposes to turn this so-called weed into treasure, using its characteristics to protect the slope. We studied the interaction between the carex roots and soil and compared it to other types of grass. To understand the interaction between the carex roots and soil, this study investigated the tensile properties of the carex root fibers. The effects of fiber content, humidity, distribution, and soil moisture content on the relationship between the shear strength and vertical pressure of the soil were analyzed using a direct shear test. Furthermore, the cohesion and internal friction angle were used to evaluate the shear strength of the root-fibered soil based on Mohr-Coulomb's law. The results showed that the smaller the diameter, the shorter the length, and the greater the quantity and the lower the humidity of the root fibers, the higher the tensile strength of root fibers. In addition, the soil strength could be improved by the joint action of the roots and the soil. With an increase in the root fiber content and humidity, the soil moisture content decreased, whereas the shear strength of the carex-root-fibered soil increased. Here, four kinds of root fiber distributions, namely, "glyph," "herringbone," "eccentric," and "vertical," were chosen to study the shear strength of the root-fibered soil. The results showed that "glyph" root fiber distribution had the highest shear strength, while the shear strength decreased for the others.
\end{abstract}

\section{Introduction}

Traditional soil slope protection schemes mainly employ engineering measures such as mortar, masonry, and concrete, which cause great environmental damage that is difficult to mitigate. In contrast, in ecological slope protection methods, plant roots play an anchoring and reinforcing role, which not only strengthens the soil slope protection but also enriches the ecosystem [1-5]. The application of ecological slope protection technology has a long history both domestically and abroad [6]. Globally, plant roots have been used commonly for slope protection [7-9]. Saifuddin and Normaniza [10] studied the mechanical properties of tropical plants and the distribution of root systems and found that fruit trees and wild peonies have a strong ability to reinforce shallow soil and prevent shallow slope damage. Saifuddin and Osman [11] found that the root system of $A$. sinensis contains high $\alpha$-cellulose content and has excellent hydraulic properties and root structure, thus, could be used for slope reinforcement.

The strength of the soil mainly manifests as shear strength, and the interaction between plant roots and soil can effectively improve the strength of soil [12-14]. Zhang et al. [15] studied the positive effect of black locust roots on the shear strength of loess intersections through triaxial compression tests. The test results showed that black locust roots could significantly increase the shear strength of soil and enhance soil cohesion considerably at the angle of internal friction. Mickovski et al. [16] and Mao et al. [17] used two-dimensional and three-dimensional finite element methods, respectively, to simulate the stress-strain relationship of plain soil and root-soil composite samples under 
a direct shear test. Their results showed that the roots could significantly enhance the shear strength of the soil. Quan et al. [18] found that roots can improve the shear strength of soil due mainly to an increasing cohesive strength which has little effect on the internal friction angle. Cohesion of a rootsoil complex is generally higher than that of plain soil. The root-soil cohesive strength with six vegetation increases from $3.14-16.51 \mathrm{kPa}$ to $9.43-28.30 \mathrm{kPa}$. Bordoloi et al. [19] proposed root ribs that resist the deformation of soil. Fan CC and Su Cf [20] studied the influence of soil moisture content on the shear strength of Zanthoxanthes root-reinforced soil. The test results showed that the root efficiency (the ratio of the additional shear strength provided by the root to the baseline shear strength of the soil) could reach more than 1.0 when the soil was in a state of high saturation.

Plant roots play a role in soil consolidation and slope protection by improving the soil stress state [20-22]. Root reinforcement performance depends on root morphology, number, diameter, water content, and so on [23-27]. The tensile strength of root fibers is positively correlated with the shear strength of the root-fibered soil [28]. Li et al. [29] used the field excavation method to conduct in situ tests on the tensile properties of a root-soil complex in the source area of the Yellow River and found that the tensile strength of a single root and the ratio of root to soil area played an important role in improving the tensile strength of the rootsoil complex. Wang et al. [1] studied the influence of the biomechanical effects of the roots of Populus tomentosa, black locust, and Chinese pine on slope stability and calculated the contribution of root cohesion to the safety factor. Fan and Chen [30] carried out in situ shear tests on a rootsoil complex and analyzed the shear strength of the root-soil complex under different root distribution conditions. The results showed that the shear strength of a root-soil complex with significant lateral roots and vertical roots increased more than that of a root-soil complex with only lateral roots. Leung et al. [31] conducted experiments on six trees of a similar age under light and no-light conditions and found that root water absorption had a relatively small contribution to plant soil-induced suction, and root water absorption had a relatively small impact on the soil water retention curve. Veylon et al. [32] used the direct shear box test method to study three tree species of reforestation on slopes in Yunnan and quantified the influence of soil water content on soil reinforced by plant roots. The structural characteristics of the roots influence the type of mechanical reinforcement (cohesion or friction).

Carex is a common herb and is often treated as a weed. It is easy to prune and resistant to cold, drought, and trampling. Therefore, it can be used as a raw material for soil consolidation and slope protection methods. The stem and soil form a kind of natural root fiber soil composite material, which improves the mechanical properties of soil. Although some scholars have tried to study the interaction between plant roots and soil mass, the systemic analysis of the mechanical reinforcement mechanism and the contribution of plant roots to strengthening the soil mass on the surface of the slope is untapped. The effects of weed fiber content, moisture, distribution, and soil moisture content on root strength and root-soil mixture were studied here. This study provides comprehensive data on nursing root mechanical properties, which are very useful in engineering practice. The role of weed roots in slope protection under different natural conditions has not been considered in the literature yet. Therefore, this study is the first that uses carex, a widely recognized weed, as the test material of root composite soil to study the effect of weeds on ecological slope protection. The second goal was to determine changes in root fiber strength under different conditions. The third goal was to establish how much carex-root-fibered soil would affect soil strength under different conditions.

In this experiment, a root-fibered soil composed of Shenyang local soil and carex roots was the research object. Root fibers with good growth were selected from the test area. First, the tensile properties of the root fibers were studied, and then they were mixed with the clay soil used in the test. According to the test groups, the root-fibered soil was prepared under various conditions to study the shear resistance of the carex-root-fibered soil.

\section{Materials and Methods}

2.1. Test Materials. Lush carex in the collection area with a growing period of more than one year was selected for the experiment.

The lengths and diameters of the carex root fibers are listed in Table 1. Most root fibers had a length of $10-15 \mathrm{~cm}$ and a diameter of $0.3-0.6 \mathrm{~mm}$. The test soil was taken from Shenyang, Liaoning Province $\left(41.8^{\circ} \mathrm{N}, 123.4^{\circ} \mathrm{E}\right)$, implementing national standard GBT50123-2019 [33], with a natural moisture content of $8.63 \%$, a maximum dry density of $1.948 \mathrm{~g} / \mathrm{cm}^{3}$, an optimal moisture content of $11.72 \%$, a liquid limit index of 29.47, and a plastic limit index of 16.21.

Carex root fibers were removed via vertical digging with utmost attention to avoid damaging the epidermis and other structures of the roots. After digging out the carex root fibers, the soil and other impurities on the fibers should be cleaned up. Different humidity root fibers were prepared according to the requirements of the experimental design.:

(1) Preparation of fresh roots: the fresh roots must be preserved. The carex roots were carefully dug out, and then their surfaces were cleaned. According to the design requirements of the experimental group, the required length was measured with a ruler and cut horizontally. In addition, the fibrous roots on the main roots were trimmed.

(2) Preparation of soaked roots: the fresh roots were immersed in an open container of room temperature water. The soaking time of fresh roots was controlled according to the design requirements of the experimental groups. After the required time lapse, the roots were taken out and trimmed to a length of $7 \mathrm{~cm}$. The soaking treatment method is shown in Figure 1.

(3) Preparation of air-dried roots: the fresh roots were cut into $7 \mathrm{~cm}$ long pieces according to the test requirements. When there was sufficient sunlight, they 
TABLE 1: Statistical table of lengths and diameters of root fibers.

\begin{tabular}{|c|c|c|c|c|c|}
\hline Root fiber length $(\mathrm{cm})$ & Quantity (root) & Proportion & Root fiber diameter $(\mathrm{mm})$ & Quantity (root) & Proportion \\
\hline $3-5$ & 6 & $3 / 25$ & $\begin{array}{lll}0.1 & 0.3\end{array}$ & 6 & $1 / 5$ \\
\hline $5-10$ & 15 & $3 / 10$ & 0.30 .6 & 12 & $2 / 5$ \\
\hline $10-15$ & 22 & $11 / 25$ & 0.60 .8 & 8 & $4 / 15$ \\
\hline $15-20$ & 7 & $7 / 50$ & 0.81 .0 & 4 & $2 / 15$ \\
\hline
\end{tabular}

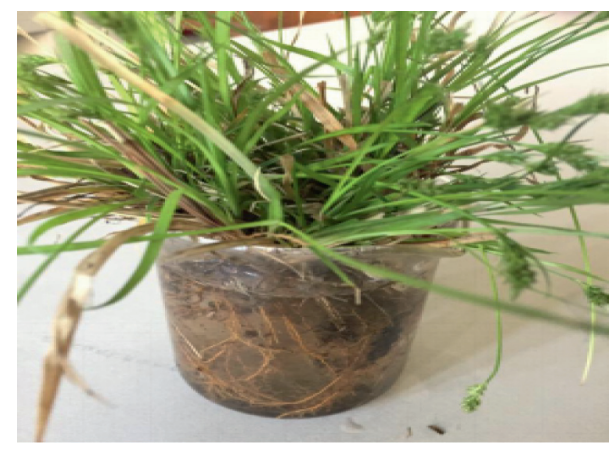

FIGURE 1: Water immersion-treated root fibers.

were dried in a well-ventilated environment with respect to a controlled air-drying time.

2.2. Test Instruments. In our test, the main instruments used were the ALGOL tautness meter ZP-10N and SDJ-1 threespeed electric constant strain direct shear apparatus. The accuracy of the ALGOL tautness meter ZP-10N is $0.05 \mathrm{~N}$. The two ends of the frame of the tautness meter were equipped with clamps for securing the root fibers. The force ring rate-setting coefficient of the SDJ-1 three-speed electric constant strain direct shear apparatus is $C=1.860 \mathrm{kPa} /$ $0.01 \mathrm{~mm}$. Other instruments in the test were a spiral micrometer with a precision of $0.03 \mathrm{~mm}$, force component of $0.01 \mathrm{~mm}$, and measuring range of $200 \mathrm{~mm}$; ruler with a precision of $0.5 \mathrm{~mm}$ and measuring range of $20 \mathrm{~cm}$; ring knife with a diameter of $61.8 \mathrm{~mm}$, bottom area of $30 \mathrm{~cm}^{2}$, and height of $20 \mathrm{~mm}$; filter papers, filter stones, dynamometer, and so on. The ALGOL tautness meter ZP-10N and SDJ-1 three-speed electric constant strain direct shear apparatus are shown in Figure 2.

\subsection{Test Methods}

2.3.1. Tensile Property Test of Carex Root Fibers. According to the test requirements, the tensile properties of the carex root fibers were cataloged using an orthogonal test. The diameter, length, quantity, and humidity of the carex root fibers were taken as the control parameters to study the tensile properties of the carex root fibers under different conditions.

To study the influence of root fiber diameter on the tensile properties of a single root, natural moisture roots with different diameters and constant lengths of $7 \mathrm{~cm}$ were selected for the experiment. Another experiment was conducted to test the influence of the length of the carex root fibers with natural humidity on the tensile properties of a single root. The length measures for the experiment were 5, $7,9,11$, and $13 \mathrm{~cm}$.

The tensile properties of single and double root fibers were compared and analyzed using root fibers of similar diameters. Carex root fibers were soaked and air-dried for $2 \mathrm{~h}$ and $4 \mathrm{~h}$ to analyze the tensile properties of the carex root fibers at different humidity levels.

\subsubsection{Shear Resistance Test of Carex-Root-Fibered Soil.} The shear resistance test of the carex-root-fibered soil was categorized regarding the method of control variables, which were the content of carex root fibers, the humidity of the carex root fibers, the moisture content of the soil, and the distribution form of the carex root fibers. We used an indoor direct shear test to analyze the two indicators, namely, cohesion and internal friction angle, to study the changes in the shear strength of root-fibered soil under different conditions. According to various influencing factors of the test design, referring to the geotechnical test specification GBT50123-2019 [33], a ring knife with a diameter of $61.8 \mathrm{~mm}$, a bottom area of $30 \mathrm{~cm}^{2}$, and a height of $20 \mathrm{~mm}$ was used to prepare test specimens.

During the test, the content of carex root fibers was determined by measuring the number of carex roots. Rootfibered soils containing $0,10,15$, and 20 roots (the soil moisture content was $11.72 \%$, and the root fiber distribution form was vertical) were selected for the direct shear test. The treatments of different humidity carex root fibers were air drying for $2 \mathrm{~h}$, air drying for $4 \mathrm{~h}$, water soaking for $2 \mathrm{~h}$, and water soaking for $4 \mathrm{~h}$. Under different humidity conditions, the shear strength of the carex-root-fibered soil was compared to the baseline to analyze the shear performance of the soil. During the next test, test soils with water contents of $7.74 \%, 11.72 \%$, and $17.31 \%$ were prepared. The number of carex root fibers was kept constant at 10 roots with the vertical distribution method. The influence of soil moisture content on the shear resistance of carex-root-fibered soil was studied.

The carex root fibers belong to whisker roots, and their distribution patterns are shown in Figure3(b). In this study, a "glyph" root-fibered soil was prepared to simulate the carex-root-fibered soil. Three forms of root-fibered soil, "herringbone shape," "biased shape," and "vertical shape," are prepared to simulate the root-fibered soils of other plants. The quantity of carex root fibers was selected as 10 , and the moisture content of the test soil was $11.72 \%$. A direct shear test was conducted to compare and analyze the influence of the distribution form of root fiber on the shear strength of the root-fibered soil, as shown in Figures 3(a) and $3(\mathrm{c})-3(\mathrm{f})$ : 


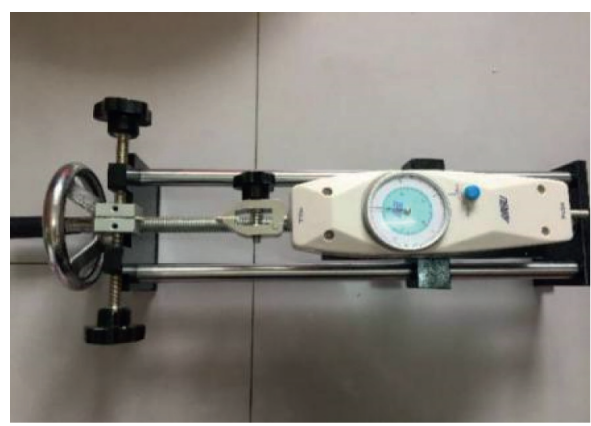

(a)

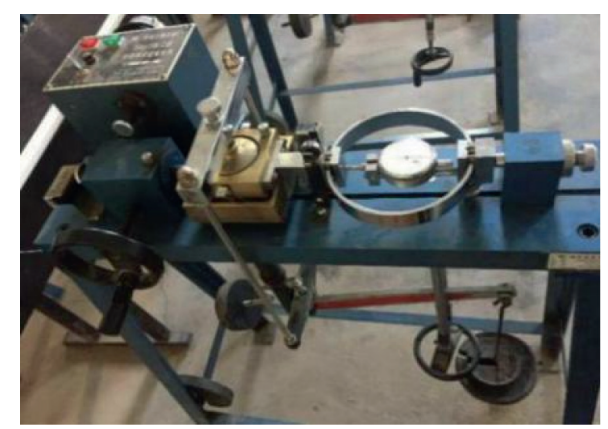

(b)

FIgUre 2: The main test instruments. (a) ALGOL tautness meter ZP-10N. (b) SDJ-1 three-speed electric constant strain direct shear apparatus.
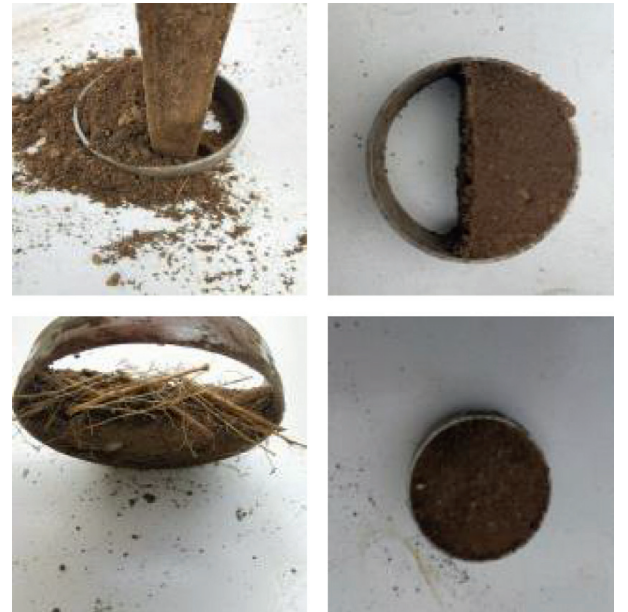

(a)

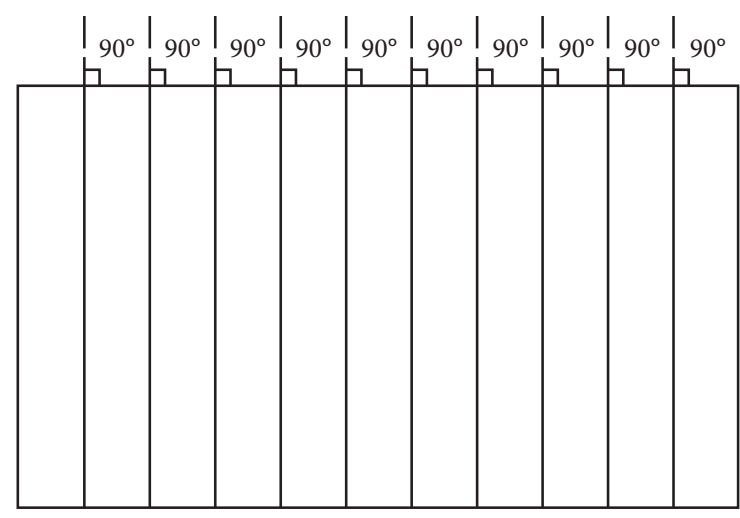

(c)
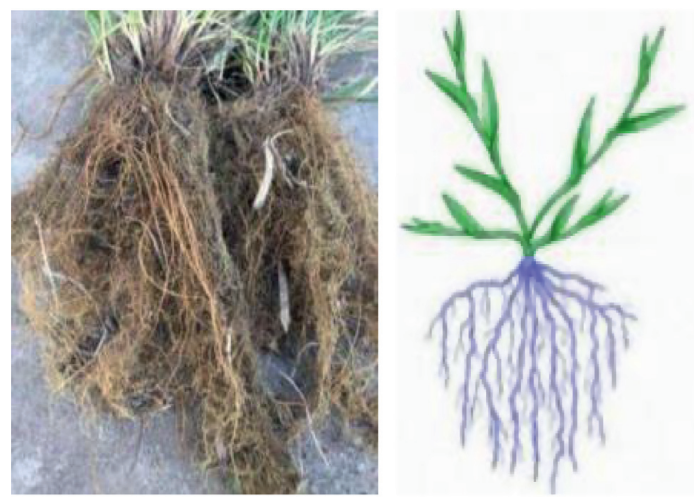

(b)

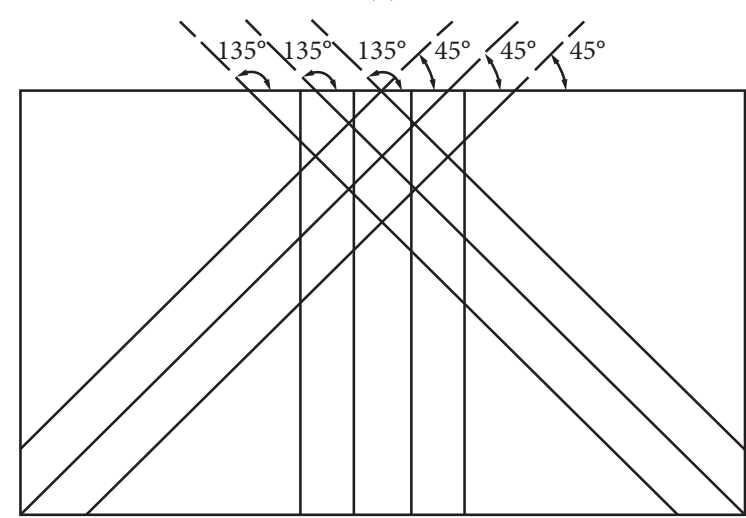

(d)

FIGURE 3: Continued. 


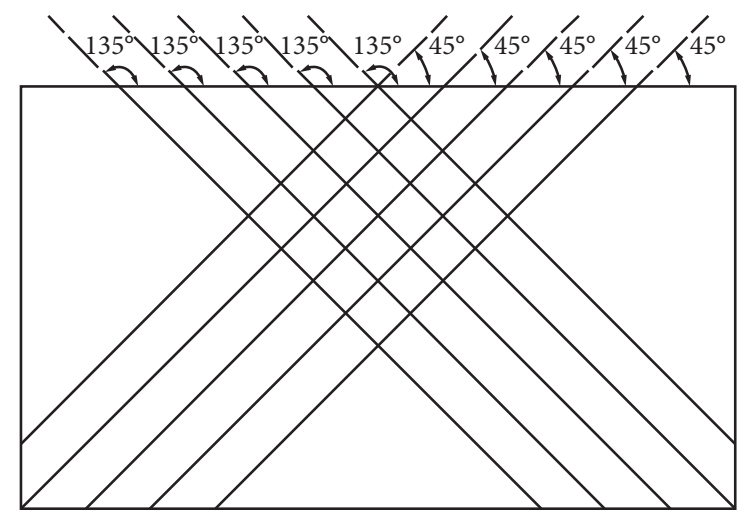

(e)

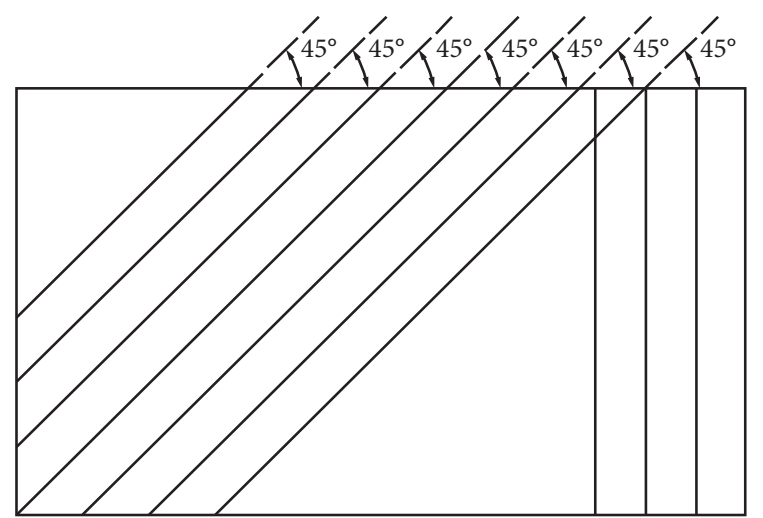

(f)

Figure 3: Root fiber distribution patterns. (a) Direct shear test sample of root-fibered soil. (b) Schematic diagram of whisker roots. (c) Vertical shape. (d) Glyph. (e) Herringbone distribution. (f) Biased shape.

\subsection{Test Process}

2.4.1. Tensile Property Test of Carex Root Fibers. The diameter of the root fiber sample was measured using a spiral micrometer. To reduce the measurement error of a given root fiber section, the average value of three measurements was taken as the measured diameter. The tension meter and bracket were fixed horizontally on the table and the dial of the tension meter was adjusted to zero. The two ends of the carex root fibers were wrapped with a paper towel and then clamped at $1 \mathrm{~cm}$ at each end. This ensured that, during stretching, the root fibers were always in axial tension. The wheel of the tensiometer was shaken at a constant speed to make the tensiometer stretch the root fibers at a uniform velocity. When the carex root fibers broke, the data from the tension meter dial were recorded, which signified the maximum tensile stresses of the carex root fibers. During the test, the carex root fibers may break at both ends of the clamp or slip out of the fixture. In this test, data were considered valid when a single root was broken at one end or near the middle of the clamp to ensure that the root fracture was caused by tension rather than any other damage in the test process.

To measure the diameter of the fracture surface of root fibers, data processing was carried out according to the calculation formula of root fiber tensile strength, which is given as follows $[34,35]$ :

$$
p=\frac{4 F}{\pi d^{2}}
$$

where $P$ is the tensile strength ( $\mathrm{MPa}$ ), $F$ is the breaking load $(\mathrm{N})$, and $D$ is the diameter of the root fiber $(\mathrm{mm})$ after the treatment but before the tensile test [36].

2.4.2. Shear Resistance Test of Carex-Root-Fibered Soil. The soil samples were prepared using a geotechnical cutter. Permeable stone and filter paper were placed in the lower part of the shear box. The ring cutter of the sample was placed and aligned in the upper box of the shear box. The permeable stone and filter paper were placed on the sample, and the permeable stone was pressed vertically. The sample was pressed into the shear box, and the piston, steel ball, and vertical load device were placed on the sample. The handwheel was slowly turned so that the dial indicator just touched the transmission device, and the initial value of the dial indicator was adjusted to zero. Vertical pressure was applied, at intervals of $50 \mathrm{kPa}, 100 \mathrm{kPa}, 150 \mathrm{kPa}$, and $200 \mathrm{kPa}$. The shear speed was $0.8 \mathrm{~mm} / \mathrm{min}$. After the handwheel started to rotate, the reading on the dial gauge at every turn was recorded. If there was no peak value on the dial indicator, the shear stress corresponding to a shear displacement of $40 \mathrm{~mm}$ was considered as the shear strength of the sample. According to $[33,37,38]$ when the shear displacement reaches the maximum value of $40 \mathrm{~mm}$, if the sample is not destroyed, it can well reflect the mechanical properties of the root fiber soil.

The test data were analyzed, and the shear displacement and stress were calculated using the following equations:

$$
\Delta L=20 n-R .
$$

Here, $\Delta L$ is the shear displacement $(0.01 \mathrm{~mm}), n$ is the rotation number of the handwheel, and $R$ is the reading of the dial indicator.

$$
\tau=C R \text {. }
$$

Here, $\tau$ is the shear stress $(\mathrm{kPa})$, with one decimal place reserved, and $C$ is the calibration coefficient of the dynamometer $(\mathrm{kPa} / 0.01 \mathrm{~mm})$.

\section{Results and Discussion}

\subsection{Tensile Properties of Carex Root Fibers}

3.1.1. Influence of Carex Root Fiber Diameter on Tensile Properties of Single Root Fibers. According to measurements, the diameter of root fibers mainly ranged between 0.19 and $0.40 \mathrm{~mm}$, and the maximum tensile stress of a single root fiber mainly ranged between 1.68 and $4.72 \mathrm{~N}$ (Figure 4). It was found that, under natural humidity conditions, the maximum tensile stress of carex root fibers increases with an 


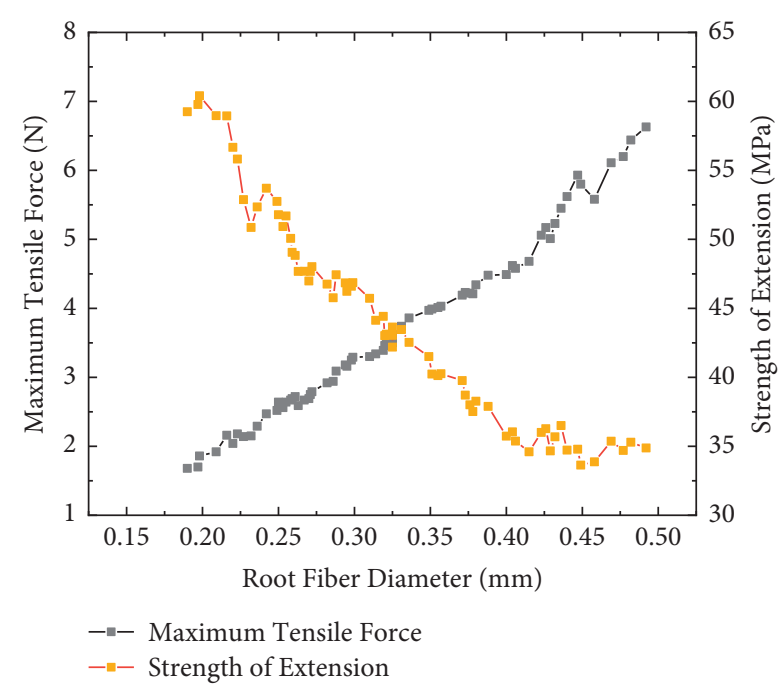

FIGURE 4: Relationship between the root fiber diameter and maximum tensile stress and tensile strength.

increase in diameter, while the tensile strength decreases for carex root fibers with an increase in diameter. This is mainly because the relationship between tensile stress and root diameter not only reflects the scaling effect in fracture mechanics but also is related to the cellulose content [39]. With an increase in root diameter, the tensile cross-sectional area increased, and the lignin and cellulose content of root fibers increased, as did the maximum tensile stress of root fibers. However, the growth rate of the maximum tensile stress was less than that of the diameter [40-42]. According to formula (1), when the growth rate of the root fiber tensile stress is less than that of the diameter, the tensile strength of the fibers decreases (Figure 4).

3.1.2. Influence of Carex Root Fiber Length on Tensile Properties of Single Root Fibers. By comparing the maximum tensile stress and tensile strength of single root fibers of different lengths at the same humidity level, it can be seen from Figure 5 when the average diameter of the root fibers is similar. The maximum tensile stress and tensile strength of a single root fiber decreased with an increase in the fiber length. The maximum tensile stress of root fibers with a length of $5 \mathrm{~cm}$ was approximately twice those of $13 \mathrm{~cm}$, and the tensile strength was approximately 2.2 times those of $13 \mathrm{~cm}$. This is mainly because the diameter of the root fibers is not uniform. With an increase in the root fiber length, the size increase of the tip became relatively large, leading to a decrease in tensile strength and a decrease in tail size, which led to a decrease in the maximum tensile stress. When the root fiber length was different, the change trends of the tensile strength and diameter were also different. The shorter the root fibers were, the greater the reduction in tensile strength with an increase in root diameter was, while the longer the root fibers were, the smaller the change range was.

3.1.3. Influence of Number of Carex Root Fibers on Tensile Properties. The tensile relationship between single root fibers and double root fibers under natural humidity is shown

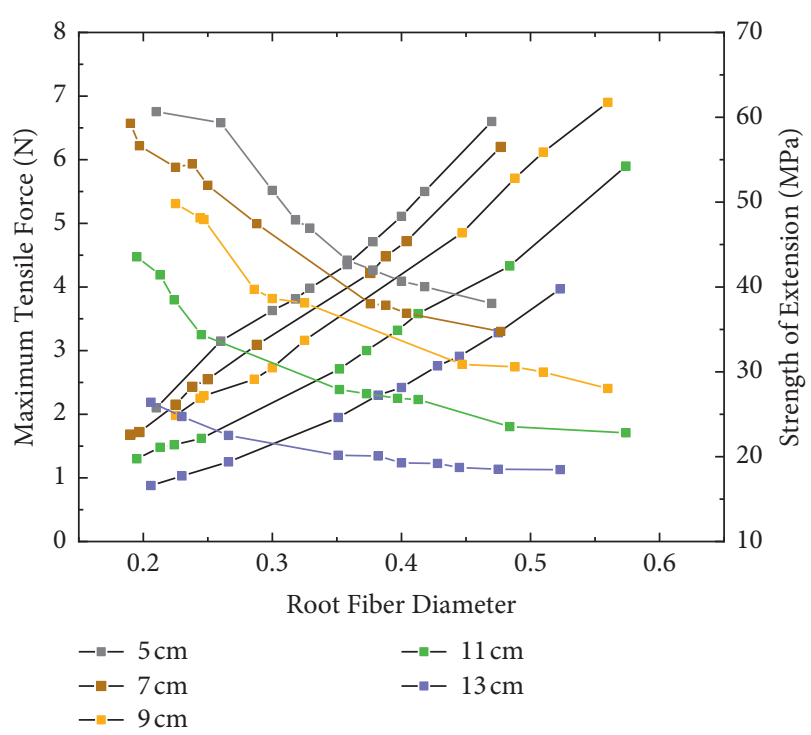

FIGURE 5: Relationship between the root fiber length and maximum tensile stress and tensile strength.

in Figure 6. It is observed that the number of root fibers has a significant effect on the maximum tensile stress and tensile strength. When the average diameter of a single root fiber is similar, the maximum tensile stress and tensile strength of double root fibers are approximately 2 times those of single root fibers. With an increase in the number of root fibers, the larger the total cross-sectional area, the higher the content of lignin and cellulose in root fibers, and the higher the degree of lignification achieved, which increased the maximum tensile stress and tensile strength of the roots and improved the tensile properties.

3.1.4. Influence of Carex Root Fiber Humidity on Tensile Properties. The influence of the humidity of carex root fibers on the tensile properties is shown in Figure 7. It is seen from Figure 7 that the maximum tensile stress of carex root fibers after $4 \mathrm{~h}$ of air drying is the largest, while that of carex root fibers air-dried for $2 \mathrm{~h}$, fresh, and immersed in water for $2 \mathrm{~h}$ are marginally less, and that of root fibers after $4 \mathrm{~h}$ of immersion is the smallest. According to formula (1), the tensile strength of different root fiber humidity levels is as follows: air drying for $4 \mathrm{~h}>$ air drying for $2 \mathrm{~h}>$ fresh $>$ soaking for $2 \mathrm{~h}>$ soaking for $4 \mathrm{~h}$.

The main reason for the above phenomenon is that the root fiber humidity is changed by air drying and soaking treatment. The resulting humidity from longer carex root fiber drying time is lower, and that from longer soaking times is higher. For the same root fiber diameter, as the humidity decreases, the maximum tensile stress and tensile strength increase [43]. This is mainly because the higher the root fiber humidity, the higher the binding water content of the root fiber, the greater the distance between microcrystals and microfibers inside the roots, the lower the binding strength between cellulose microfiber and fiber in the cell wall structure, and the worse the tensile property. Under the same humidity condition, with an increase in diameter, the 


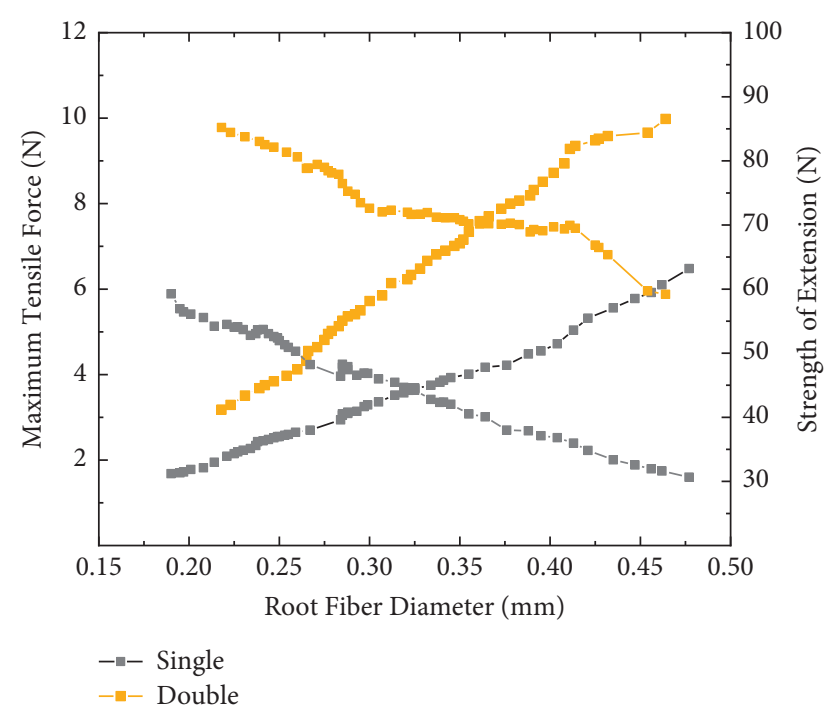

FIGURE 6: Relationship between the number of root fibers and maximum tensile stress and tensile strength.

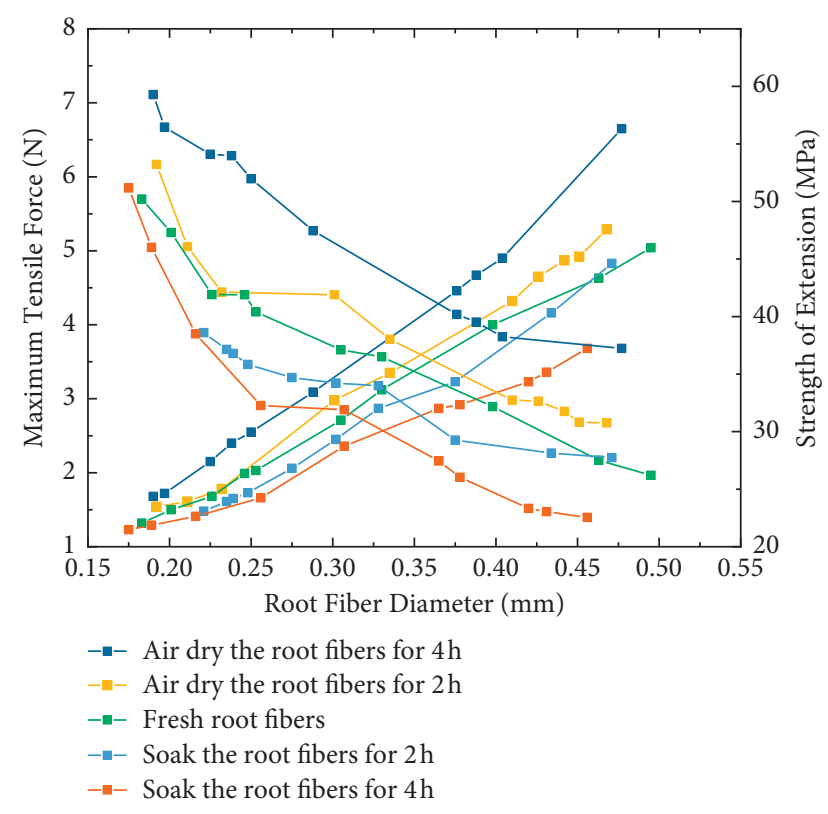

Figure 7: Relationship between the root fiber treatment and maximum tensile stress and tensile strength.

maximum tensile stress increased, while the tensile strength decreased. This indicates that the relationship between the diameter, maximum tensile stress, and tensile strength is not affected by humidity.

3.2. Shear Resistance of Root Fiber Soil. Figure 8 clearly shows that, under vertical loading of the direct shear test, shear failure occurred in the root-fibered soil, which was mainly manifested as obvious gradual dislocation of soil. The root fibers were pulled out or broken in the root fiber soil samples. Taking shear stress as the ordinate and shear displacement as the abscissa, the relation curve between the shear stress and shear displacement was drawn. Taking the peak value of shear stress or shear displacement of $40 \mathrm{~mm}$ as the shear strength, the shear strength as the ordinate, and the vertical pressure as the abscissa, the relationship curve between the shear strength and the vertical pressure was drawn, and the cohesion $c$ and internal friction angle $\varphi$ of the soil sample were obtained.

3.2.1. Influence of Root Fiber Content on the Shear Performance of Root-Fibered Soil. The direct shear test curve of root-fibered soils with different carex root fiber contents is shown in Figure 9.

Through the above data analysis, we can determine the shear resistance of root-fibered soils with different root fiber contents. The relationship between shear strength and vertical pressure of root-fibered soil is similar to that of plain soil. The fitting curves are all straight lines, which proves that the shear strength of the root-fibered soil satisfies the Mohr-Coulomb strength theory:

$$
\tau=c+\tan \varphi .
$$

According to Figures 9 and 10, the influence of root fiber content on the shear strength of root-fibered soil is analyzed, and the results are summarized in Table 2.

As shown in Figure 11(a), the root fiber content plays an important role in improving the shear strength of the root-fibered soil. With an increase in the root fiber content from 0 to 20 , the shear strength increased by $8-10 \mathrm{kPa}$ under different vertical stresses. In Figure 11(b), under the same conditions, with an increase in root fiber content, the cohesion increased, and the internal friction tended to be stable overall with small deviations. When the root fiber content was 10 roots, the cohesion of the soil sample increased by $2.256 \mathrm{kPa}$ compared to the plain soil. When the root fiber content increased from 10 to 15 roots, the cohesion increased by $2.974 \mathrm{kPa}$, and when the root fiber content increased from 15 to 20 roots, the cohesion increased by $5.114 \mathrm{kPa}$. With an increase in root fiber content, the cohesion increased by $30-40 \%$. The maximum difference in the internal friction angle of different root fiber contents was $0.622^{\circ}$, and the variation range was $7.51 \%$.

There are two mechanisms (mechanical action) for the increase of soil shear strength through the use of the carex root fibers [44]: (1) Reinforcement: root fibers are regarded as the reinforcement material, and the soil containing the roots is regarded as the reinforced soil. The root fibers restrain the deformation of the soil and improve its strength. (2) Anchor: the root fibers have a certain tensile strength and shear strength. When the root fibers and the soil work together, it is as if countless anchor rods are embedded in the soil, which makes the soil squeeze itself and form a whole that improves the friction resistance of the soil. With an increase in the number of roots, the overall tensile properties increase, and thus the shear strength of the root-fibered soil increases. The internal friction angle of root-fibered soil mainly depends on the particle size and roughness of the soil. The influence of plant roots on the internal friction angle is negligible. 


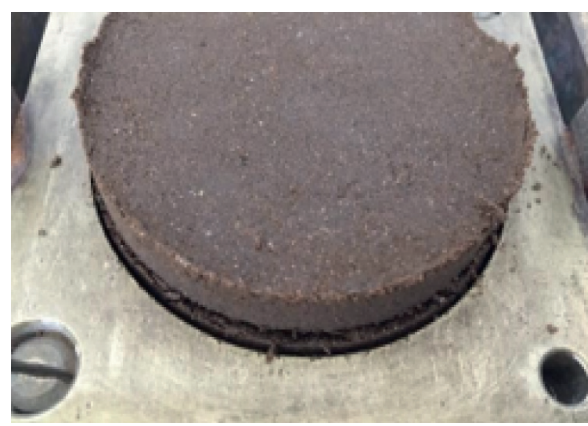

(a)

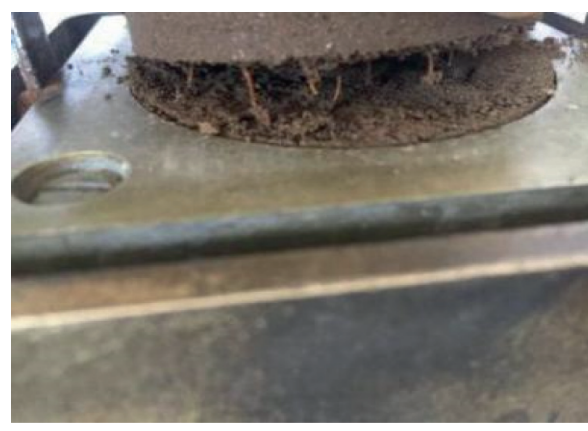

(c)

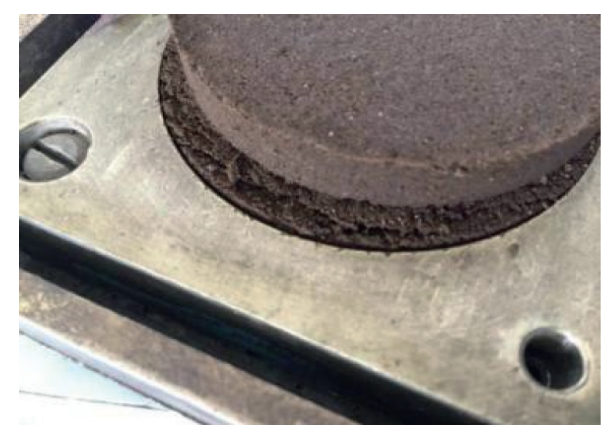

(b)

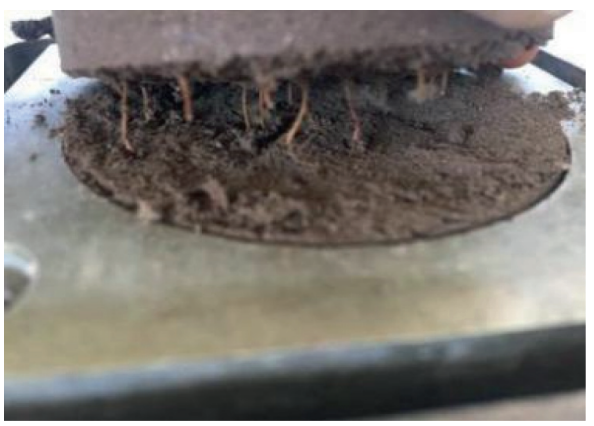

(d)

Figure 8: (a, b) Shear failure occurred in root-fibered soil. (c, d) Root fibers are pulled out or broken.

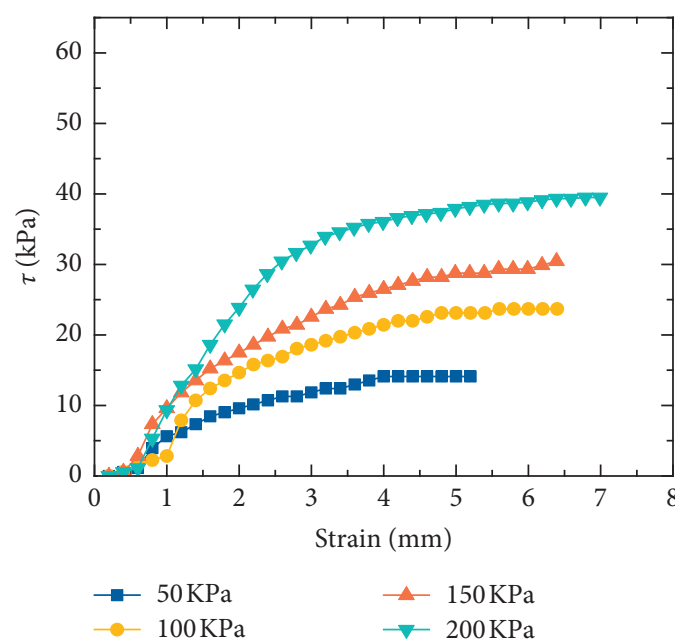

(a)

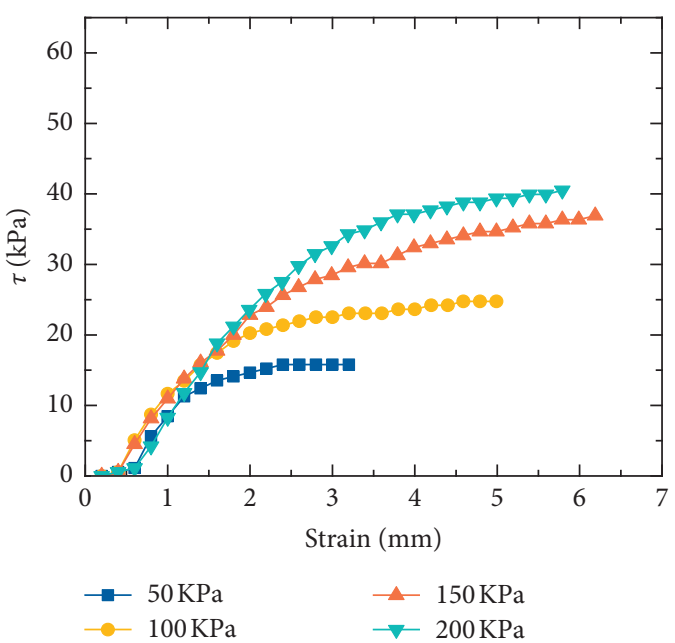

(b)

Figure 9: Continued. 


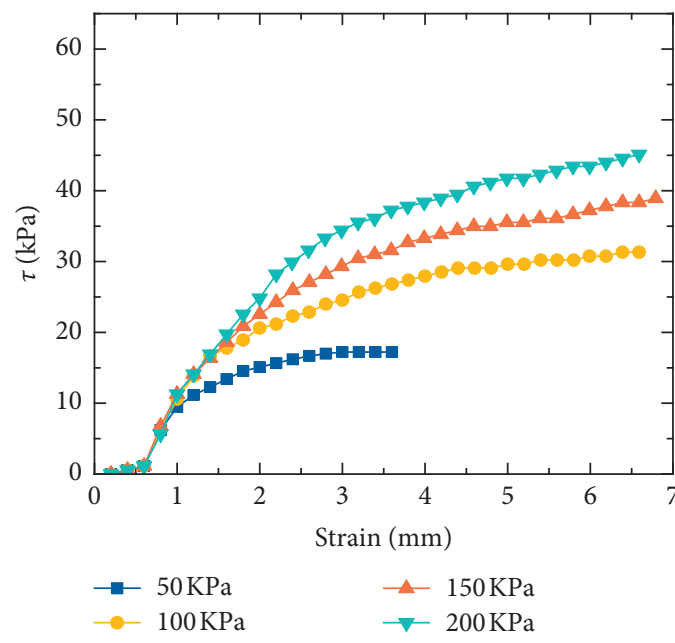

(c)

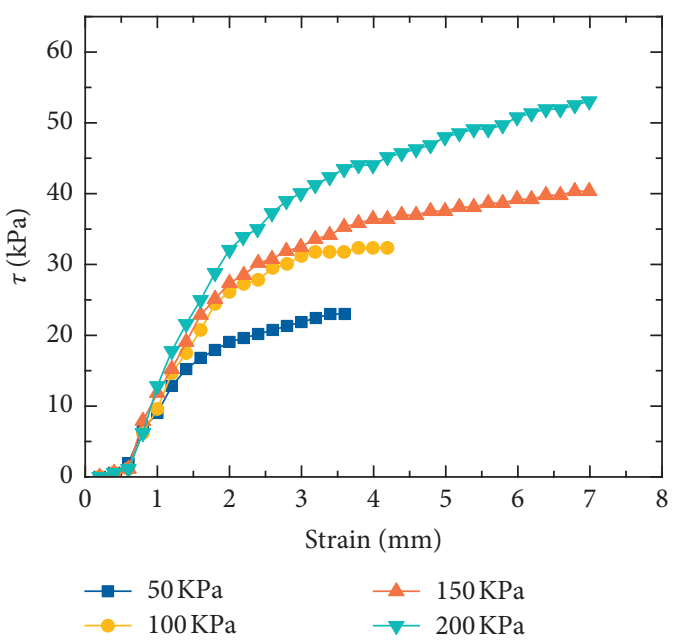

(d)

Figure 9: Shear stress-shear displacement curves of different root fibers contents. Relationship between shear stress and shear displacement of (a) plain soil, (b) 10 root fibers, (c) 15 root fibers, and (d) 20 root fibers.

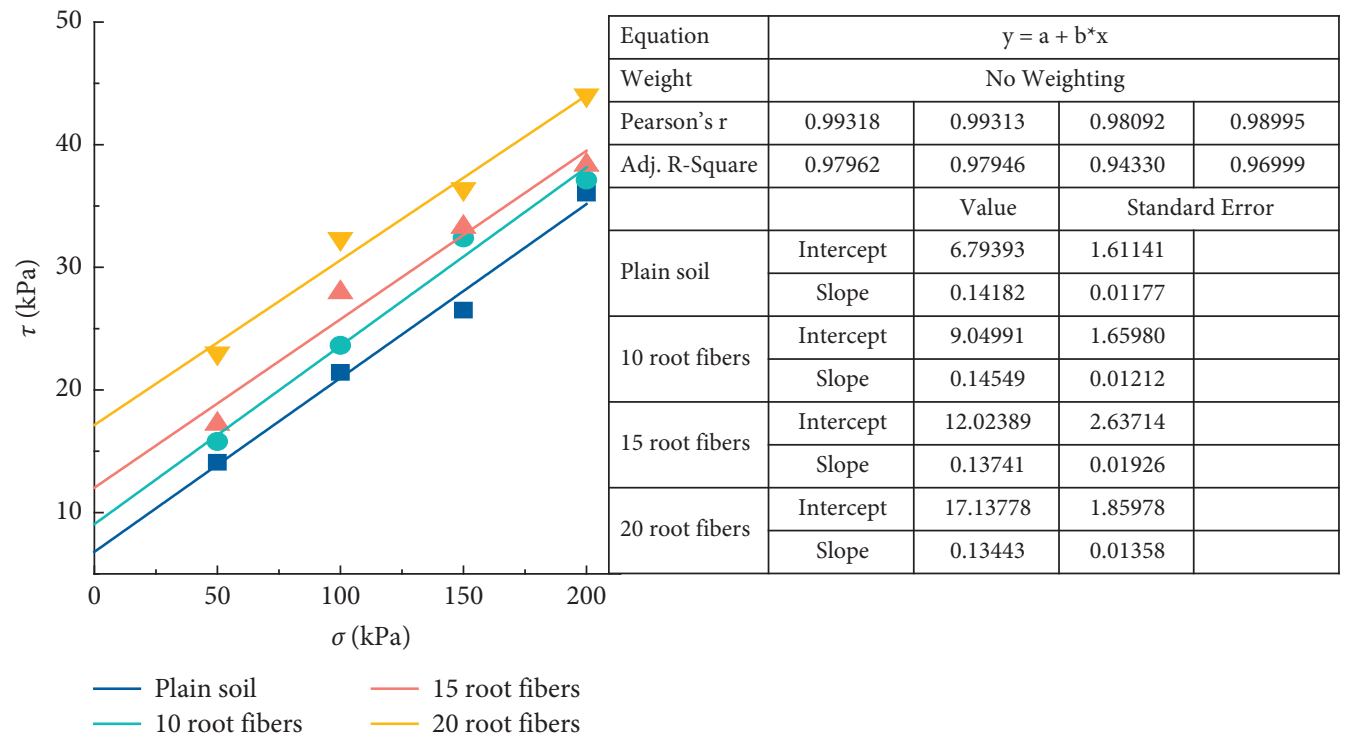

Figure 10: Relationship between shear strength and vertical stress of different root fiber contents.

TABLE 2: Comparison table of shear strength of root fibers treated in different ways.

\begin{tabular}{lccc}
\hline Root fiber content & Angle of internal friction $\left(^{\circ}\right)$ & Cohesion $(\mathrm{kPa})$ & $R^{2}$ \\
\hline 0 & 8.072 & 6.794 & 0.97962 \\
10 & 8.278 & 9.050 & 0.97946 \\
15 & 7.824 & 12.024 & 0.98092 \\
20 & 7.656 & 17.138 & 0.98995 \\
\hline
\end{tabular}

In conclusion, the root fiber content has a significant influence on cohesion but has little effect on the internal friction angle, which conforms to the principle of quasicohesion [45].

\subsubsection{Influence of Root Fiber Humidity on the Shear} Performance of Root-Fibered Soil. The shear performances of root-fibered soils with different root fiber humidity levels were analyzed, and the test data were processed according to the results of the direct shear test as shown in Figure 12.

Based on Figures 12 and 13, the shear strength performance indices of root-fibered soils with different root fiber humidity levels are compared, as shown in Table 3.

It is seen from Figure 14 that the shear strength of the air-dried carex-root-fibered soil is significantly higher than 


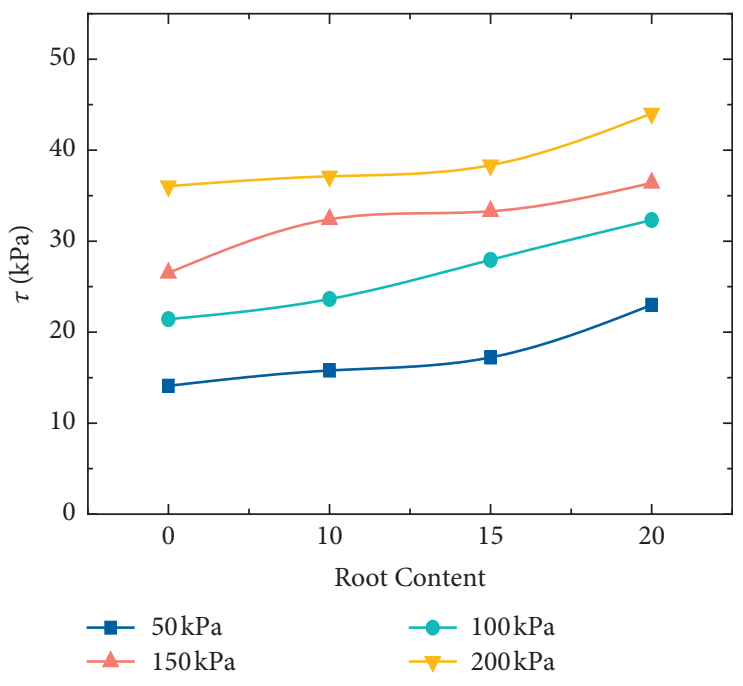

(a)

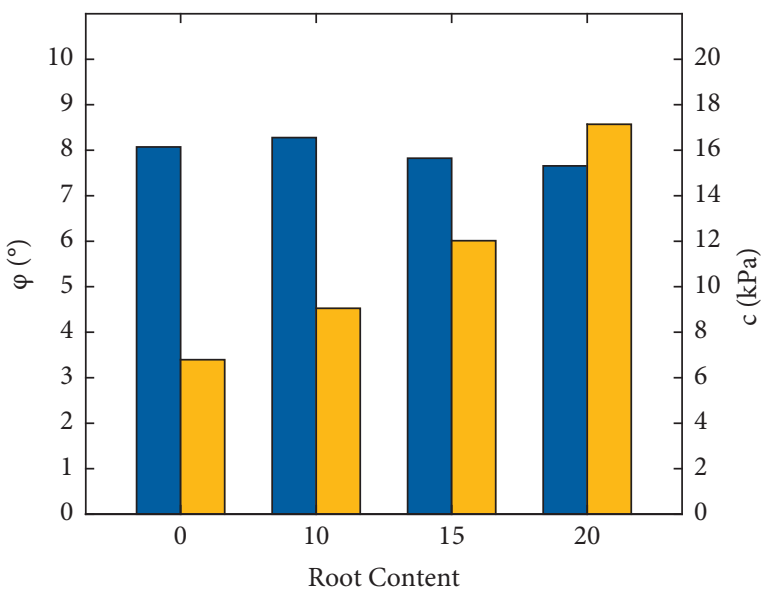

(b)

Figure 11: Influence of root fiber content on (a) the shear strength and (b) shear strength index of root-fibered soil.
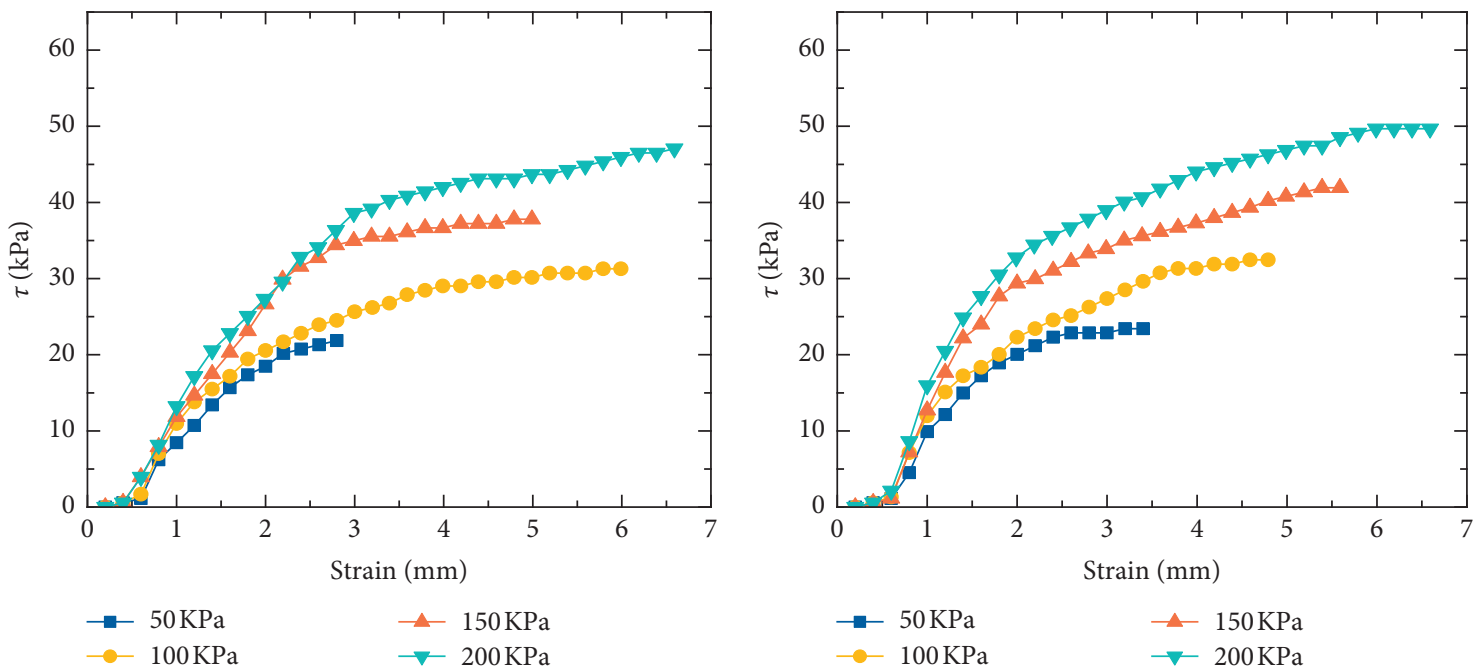

(a)

(b)

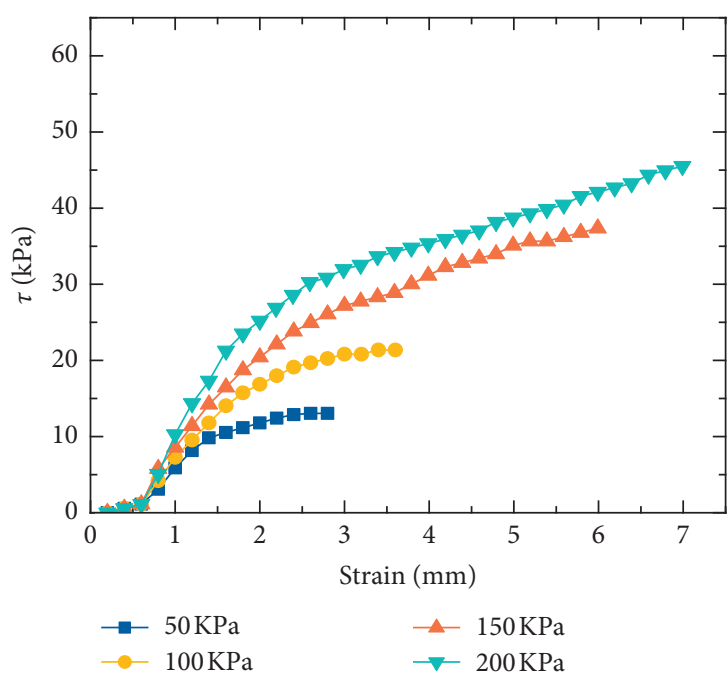

(c)

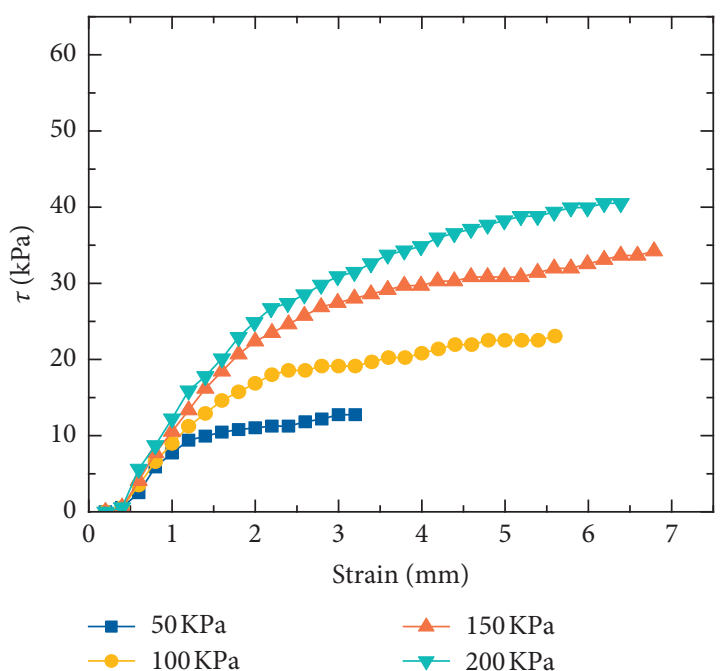

(d)

FIGURE 12: Shear stress-shear displacement curves of different root fiber humidity levels. Relationship between root fiber shear stress and shear displacement (a) after air drying for $2 \mathrm{~h}$, (b) after air drying for $4 \mathrm{~h}$, (c) after soaking for $2 \mathrm{~h}$, and (d) after soaking for $4 \mathrm{~h}$. 


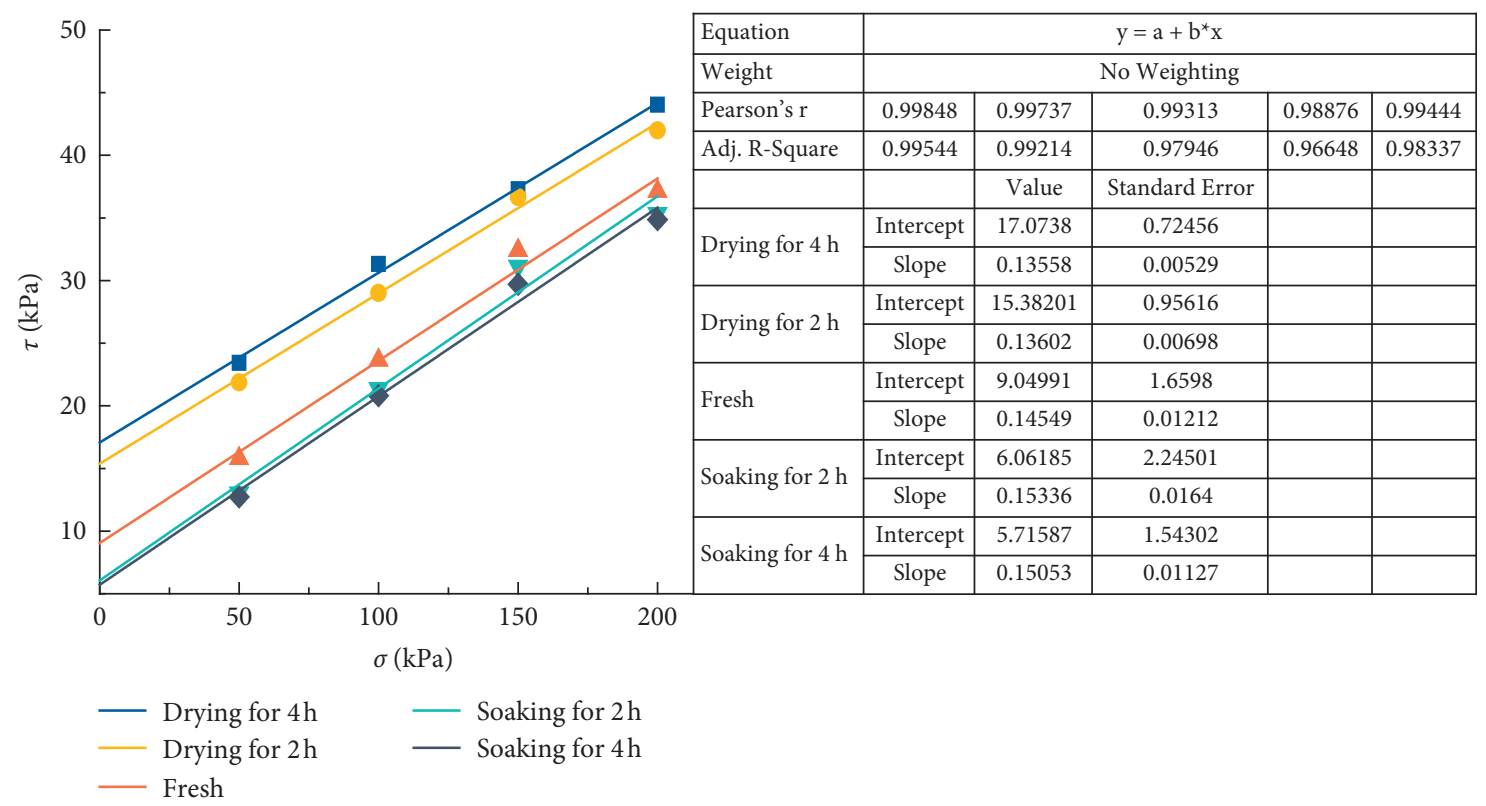

FIGURE 13: Relationship between shear strength and vertical stress of different root fiber humidity levels.

TABLE 3: Comparison of shear strength of root fibers treated in different ways.

\begin{tabular}{lccc}
\hline Root fiber treatment & Angle of internal friction $\left(^{\circ}\right)$ & Cohesion $(\mathrm{kPa})$ & $R^{2}$ \\
\hline Drying for $4 \mathrm{~h}$ & 7.721 & 17.074 & 0.99544 \\
Drying for $2 \mathrm{~h}$ & 7.746 & 15.382 & 0.99737 \\
Fresh & 8.278 & 9.050 & 0.962 \\
Soaking for $2 \mathrm{~h}$ & 8.719 & 5.716 & 0.98876 \\
Soaking for $4 \mathrm{~h}$ & 8.812 & 0.99444 \\
\hline
\end{tabular}

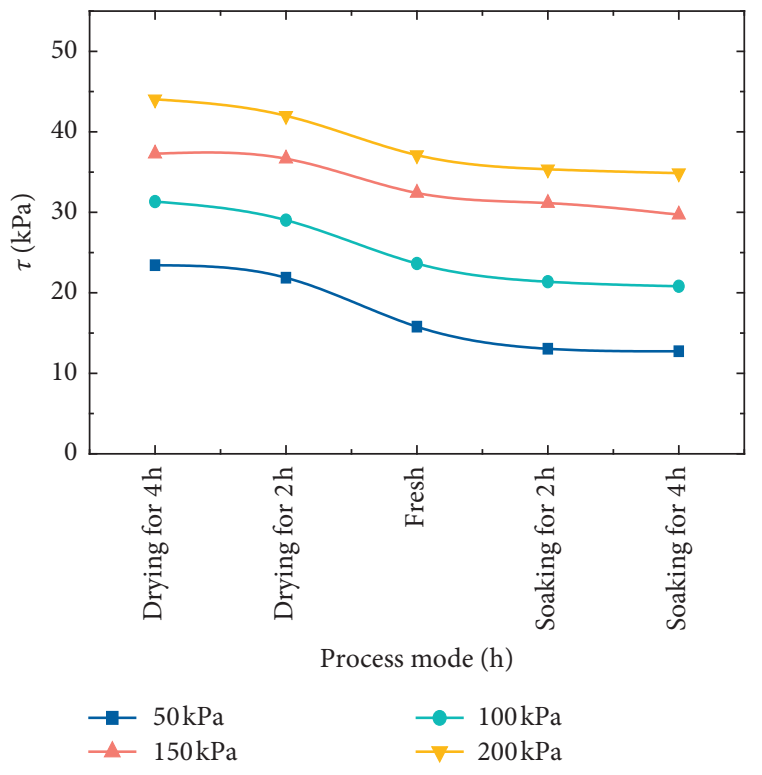

(a)

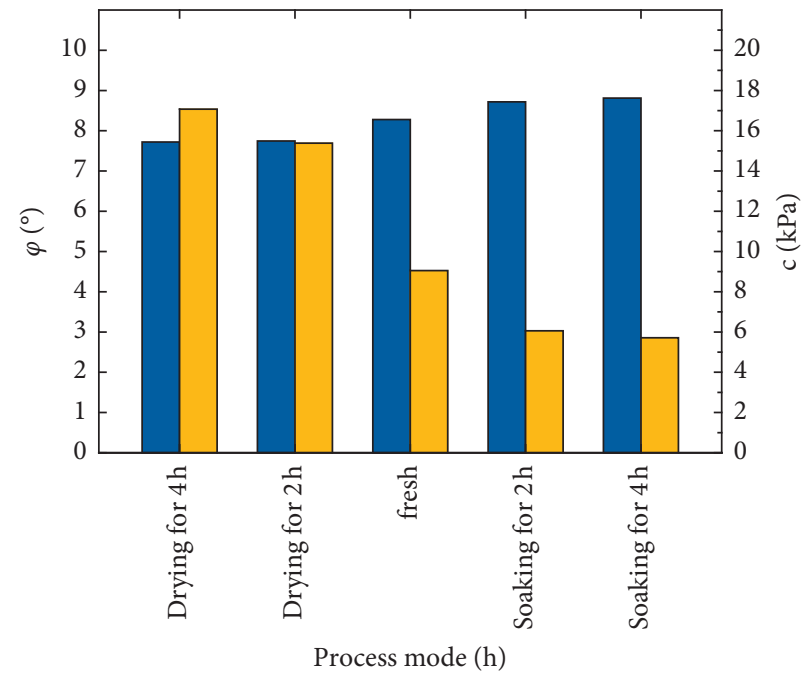

(b)

FIGURE 14: Influence of root fiber humidity levels on (a) shear strengths and (b) shear strength indices of root-fibered soils.

that of the root-fibered soil treated with water immersion. In addition, the shear strength of the root-fibered soil with low root fiber humidity is higher than that of the root-fibered soil with high root fiber humidity. Under different vertical pressures, the shear strength of the $4 \mathrm{~h}$ air-dried root-fibered soil was $6-8 \mathrm{kPa}$ higher than that of the fresh root-fibered 
soil, while the shear strength of the fresh root-fibered soil was $3 \mathrm{kPa}$ higher than that of the root-fibered soil soaked for $4 \mathrm{~h}$. The shear strength of root-fibered soil soaked for $2 \mathrm{~h}$ was less than $564 \mathrm{~Pa}$ higher than that of the root-fibered soil soaked for $4 \mathrm{~h}$. This indicates that the humidity of root fibers was nearly saturated after soaking for $2 \mathrm{~h}$; hence, the influence of continuous soaking on root fiber humidity was not significant. The cohesion of the root-fibered soil decreased with an increase in the root fiber humidity, and the internal friction angle changed little. Compared to the fresh root-fibered soil, the cohesion of the $4 \mathrm{~h}$ air-dried root-fibered soil increased by $8.024 \mathrm{kPa}$, which is an increase of $88.66 \%$. In addition, the cohesion of the $4 \mathrm{~h}$ soaked rootfibered soil decreased by $3.334 \mathrm{kPa}$, which is a decrease of $36.84 \%$. The maximum difference in the internal friction angles of different root fiber humidity levels was $0.998^{\circ}$, and the variation range was $11.45 \%$.

The lower the humidity of the root fibers, the stronger the tensile strength of the root fiber, the greater the anchoring influence of the reinforcement, and the higher the shear strength of the root-fibered soil. The internal friction angle of root-fibered soil mainly depends on the nature of the soil and has no obvious relationship with the root fibers themselves.

\subsubsection{Influence of Soil Moisture Content on Shear} Performance of Root-Fibered Soil. The influence of soil moisture content on the shear performance of the root-fibered soil was also studied. According to the experimental data processing, the experimental relation curve is obtained as shown in Figure 15.

According to Figures 15 and 16, the shear strength indices of root-fibered soil with different soil moisture contents are compared, as shown in Table 4.

The influence of soil moisture content on the shear strength of the root-fibered soil is shown in Figure 17(a). Under the same vertical stress, the shear strength of the rootfibered soil decreased with an increase in the soil moisture content. The lower the soil moisture content is, the greater the shear strength is, which is in line with the classic water film theory [46]. It can be seen from the relationship curve of soil moisture content and shear strength index in Figure 17(b) that the cohesion decreases with an increase in soil moisture content. This is because when the soil moisture content is high, the inherent attraction between particles is gradually weakened by the thickened water film, resulting in a downward trend of cohesion. Under different vertical pressures, the shear strength with a soil moisture content of $7.74 \%$ was approximately $6 \mathrm{kPa}$ higher than that with a soil moisture content of $17.31 \%$. When the soil moisture content was $7.74 \%$, the cohesion was 1.687 times of that with a soil moisture content of $17.31 \%$, increasing by $4.719 \mathrm{kPa}$, while the internal friction angle only changed by $0.329^{\circ}$, increasing by $3.94 \%$. Compared to the influence of soil moisture content on cohesion, its influence on the internal friction angle can be ignored.

The connection force of the common hydration film between soil particles and cementation of the cementing material plays an important role in the generation of cohesion. When the soil moisture content increased, an increasing number of water molecules were distributed in the pores of the soil, which reduced the cementation effect of the cementing material on the clay particles. In addition, the soil has capillary properties. Under the influence of surface tension, the water in the root-fibered soil moves upward along the finer soil pores, which further increases the lubrication between water molecules and soil particles. Lubrication can reflect the degree of particle cementation. The smaller the water content, the greater the bonding force of water film, the greater the condensation effect, and the greater the cohesive force of soil. With the increase of water content, the thickness of water film increases, the bonding effect of water film weakens, the coagulation effect decreases, and the cohesive force decreases. When the cohesion weakens to a certain extent, the cementation between particles begins to gradually lose, and the water content on the soil is mainly manifested as lubrication. This leads to a decrease in the shear strength of the carex root-fibered soil $[47,48]$. The internal friction angle of soil is mainly manifested as the surface friction of soil particles and the bite force between particles, which reflects the friction characteristics between soil particles and is related to the structure form and compactness of the soil. Many studies have shown that the factors affecting the internal friction angle of soil include the mineral composition, moisture content, density, and structure of the soil. Lu believes that the internal friction angle of soil also has a correlation with its plasticity index [49], and its mechanism is relatively complex and requires further study.

\subsubsection{Influence of Root Fiber Distribution Morphology on the} Shear Performance of Root-Fibered Soil. According to the results of the direct shear test, the test data were compared to the vertically distributed root-fibered soil in a previous study. The relationship curve was drawn after treatment, as shown in Figure 18.

According to Figures 18 and 19, the shear strength performance indices of the root-fibered soil were analyzed according to the morphological distribution of root fibers, as shown in Table 5.

The above charts, respectively, reflect the shear strength and shear strength index of the "glyph," "herringbone," and "eccentric" distributions of the root-fibered soil when root fiber content and test soil moisture are the same. Combined with "vertical" root-fibered soil direct shear test data obtained from comparison and analysis, it was found that different root fiber morphological distributions result in significantly different degrees of improvements in the shear resistance of the root-fibered soil. The results show that "glyph" distribution increased the root-fibered soil shear strength by approximately $4.8 \mathrm{kPa}$. The "eccentric" distribution resulted in an increase of approximately $3 \mathrm{kPa}$. The shear strength of "herringbone" distribution is slightly lower than that of "eccentric" distribution. In addition, the shear strength increase of root-fibered soil with "vertical" distribution was the lowest, approximately $1.5 \mathrm{kPa}$. The results 


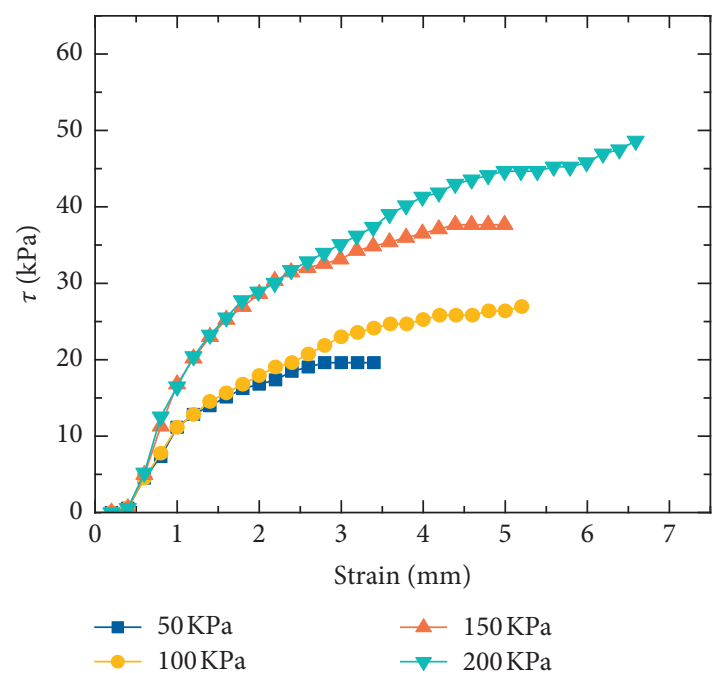

(a)

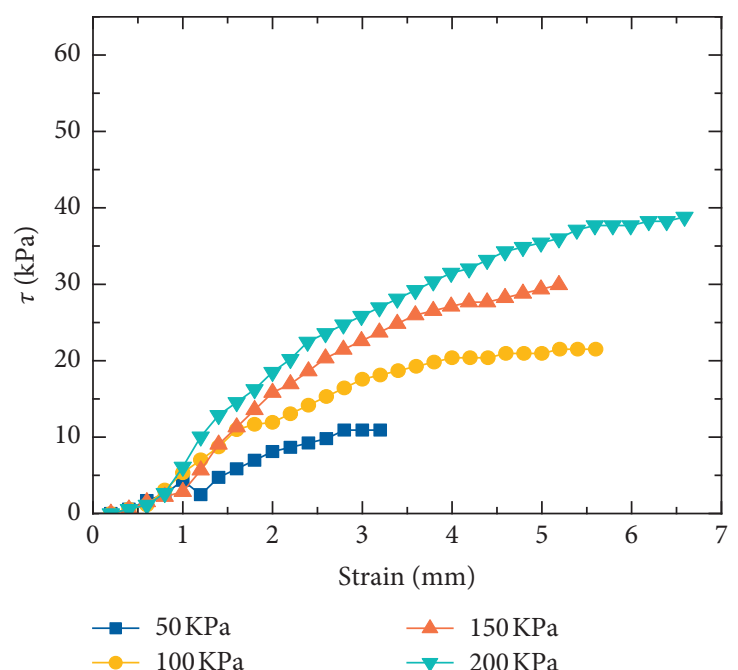

(b)

FIGURE 15: Shear stress-shear displacement curves of different soil moisture contents. The relationship between shear stress and shear displacement at a moisture content of (a) $7.74 \%$ and (b) $17.31 \%$.

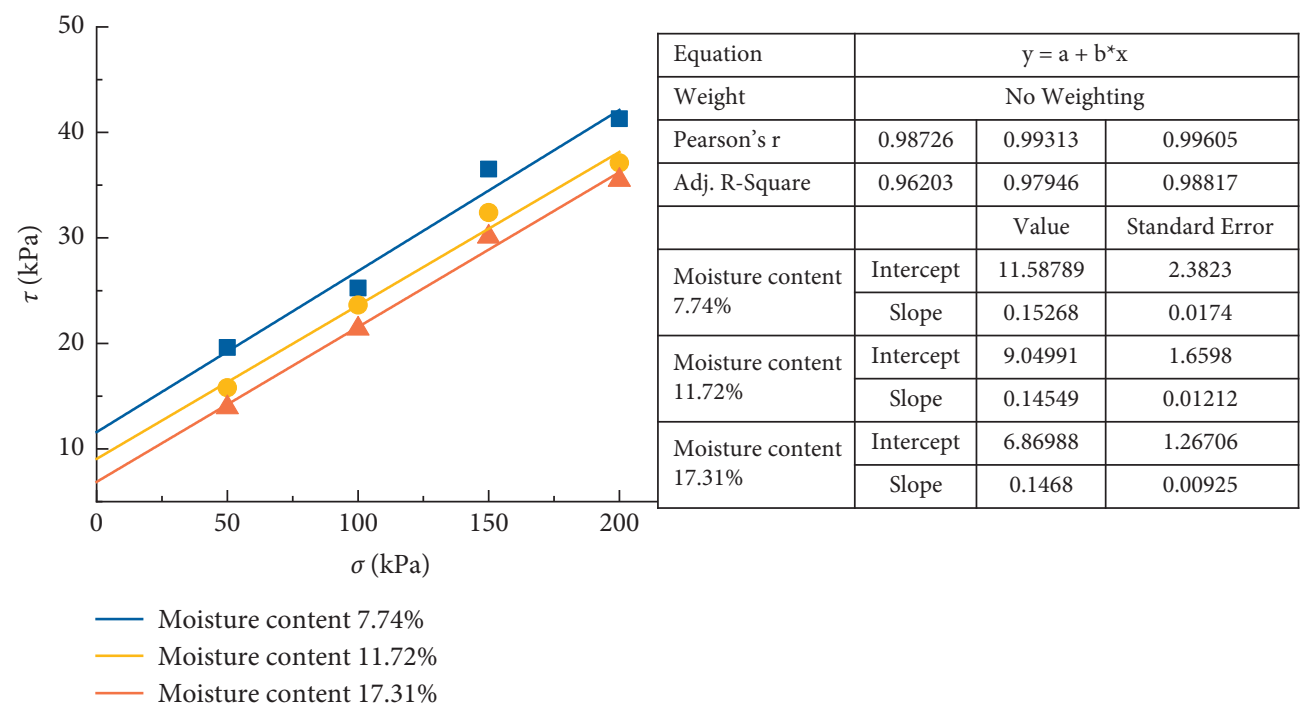

Figure 16: Relationship between shear strength and vertical stress of different soil moisture contents.

TABLE 4: Soil moisture content/shear strength comparison.

\begin{tabular}{lccc}
\hline Moisture content $(\%)$ & Angle of internal friction $\left(^{\circ}\right)$ & Cohesion $(\mathrm{kPa})$ & $R^{2}$ \\
\hline 7.74 & 8.680 & 11.588 & 0.96203 \\
11.72 & 8.278 & 9.050 & 0.97946 \\
17.31 & 8.351 & 6.869 & 0.98817 \\
\hline
\end{tabular}

show that different morphological distributions of root fibers influence the increase in the shear strength of the rootfibered soil. According to Figure 20, it is observed that the increase in the shear strength of root-fibered soil due to different root fiber morphological distributions is mainly because of the increase in cohesion. However, it has little influence on the internal friction angle. Compared to plain soil, the cohesion of "glyph," "eccentric," "herringbone," and "vertical" distributions, respectively, increased by $4.438 \mathrm{kPa}$, $2.820 \mathrm{kPa}, 2.756 \mathrm{kPa}$, and $2.256 \mathrm{kPa}$, with increase rates of $65.32 \%, 41.51 \%, 40.57 \%$, and $33.21 \%$. In the test, the maximum internal friction angle belonged to the "herringbone" distribution at $8.656^{\circ}$, which only increased by $0.584^{\circ}$ compared to the internal friction angle of plain soil. The 


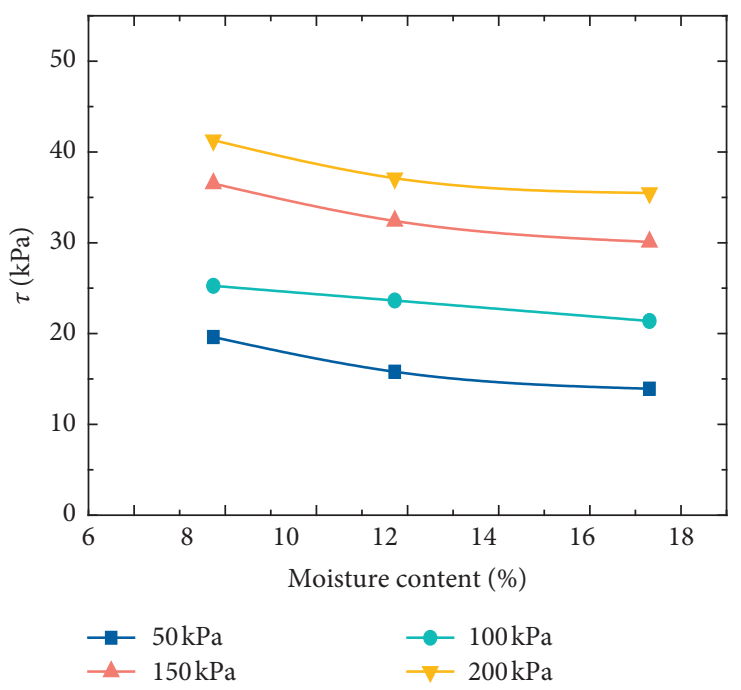

(a)

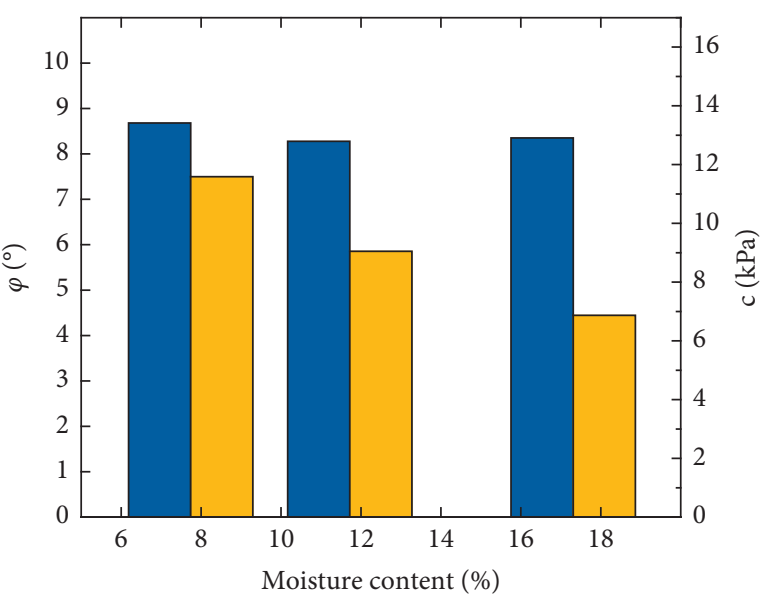

(b)

Figure 17: Influence of soil moisture content on (a) shear strengths and (b) shear strength indices of root-fibered soil.

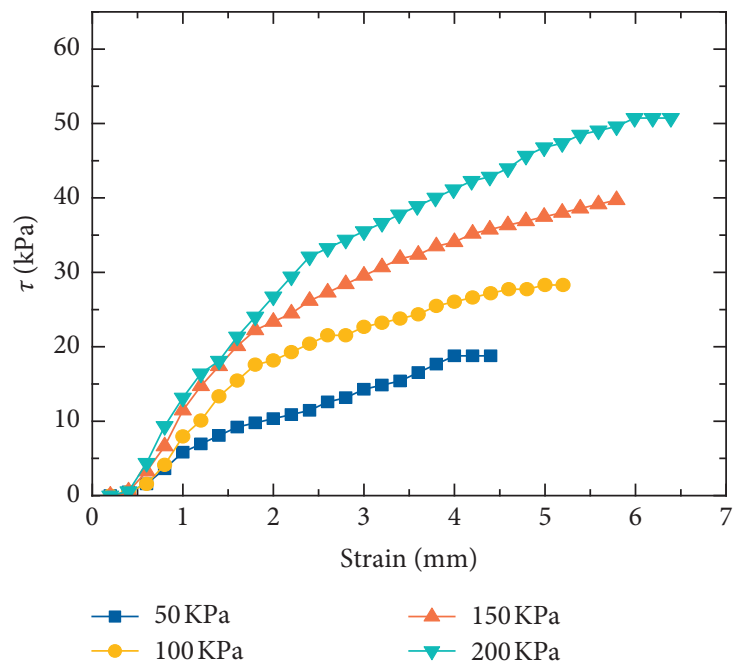

(a)

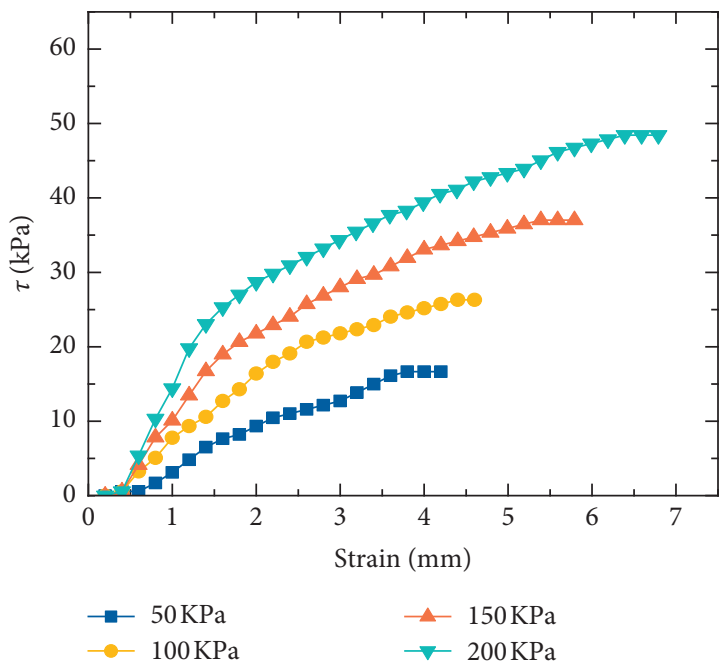

(b)

Figure 18: Continued. 


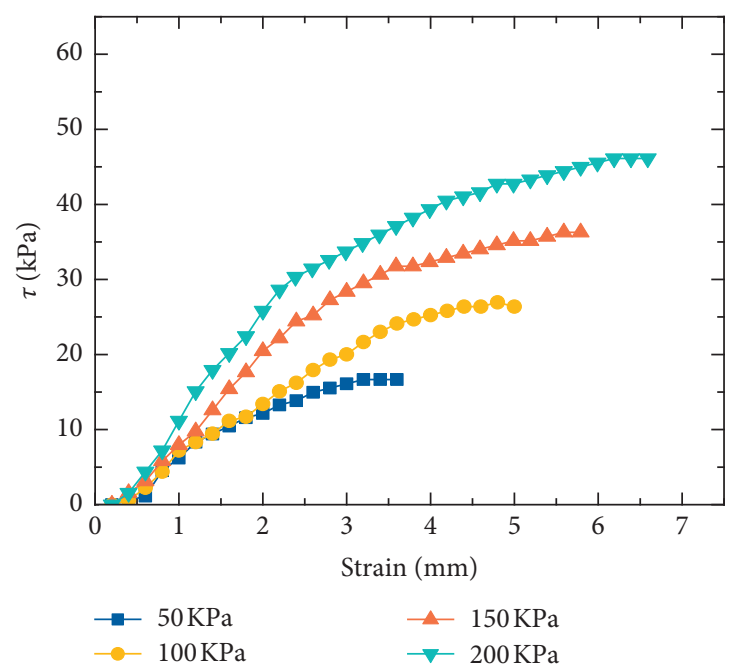

(c)

FIGURE 18: Shear stress-shear displacement curves of different root fiber morphological distributions. Relationship between the shear stress and shear displacement of the (a) glyph distribution, (b) herringbone distribution, and (c) eccentric distribution.

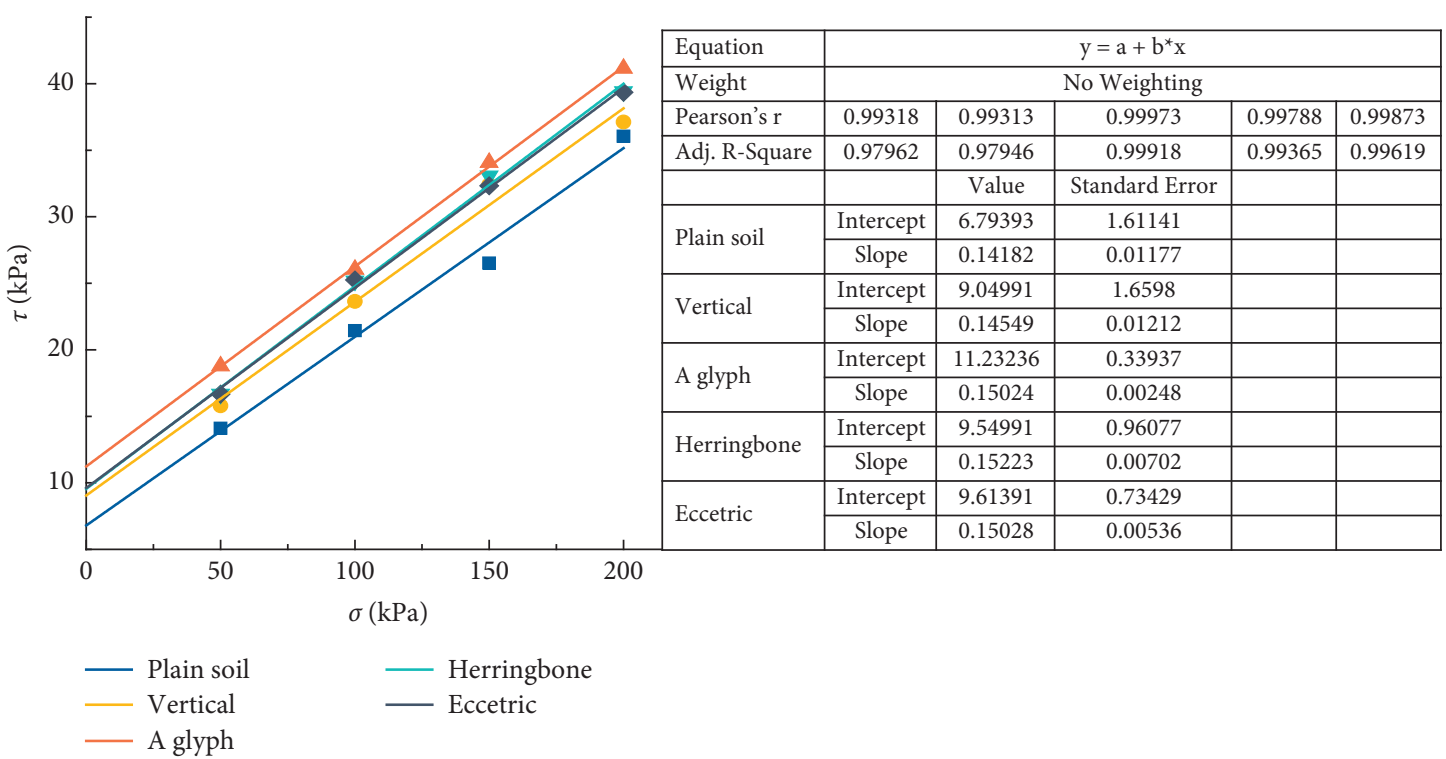

FIGURE 19: Relationship between shear strength and vertical stress of different root fiber morphological distributions.

TABLE 5: Shear strength comparison of different root fiber morphological distributions.

\begin{tabular}{|c|c|c|c|}
\hline Root fiber distribution morphology & Angle of internal friction $\left({ }^{\circ}\right)$ & Cohesion $(\mathrm{kPa})$ & $R^{2}$ \\
\hline Plain soil & 8.072 & 6.794 & 0.97962 \\
\hline Vertical distribution & 8.278 & 9.050 & 0.97946 \\
\hline A glyph distribution & 8.544 & 11.232 & 0.99918 \\
\hline Herringbone distribution & 8.656 & 9.550 & 0.99365 \\
\hline Eccentric distribution & 8.546 & 9.614 & 0.99619 \\
\hline
\end{tabular}

increase rate is $7.23 \%$. Therefore, the internal friction angle of root-fibered soil has no significant relationship with root fibers and their distribution in the soil.

The actual distribution form of the carex root fibers is closer to the "glyph" distribution. Through the direct shear test, it was found that the shear strength of the root-fibered soil with the "glyph" distribution is the largest under different vertical pressures. The main reason is that the "glyph" root fibers contact with the soil from multiple angles to form a network structure with greater stiffness that is more tightly 


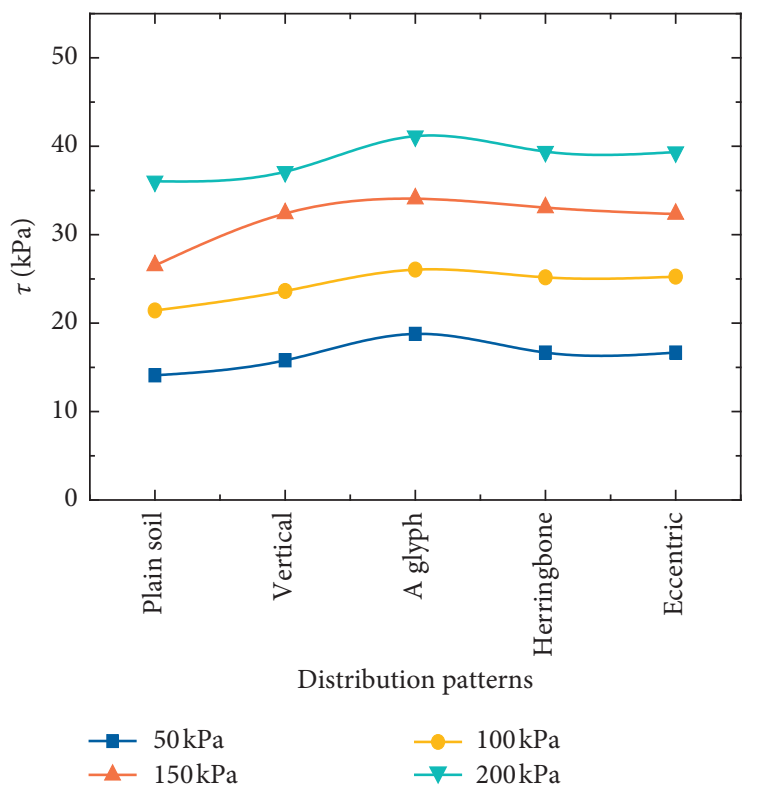

(a)

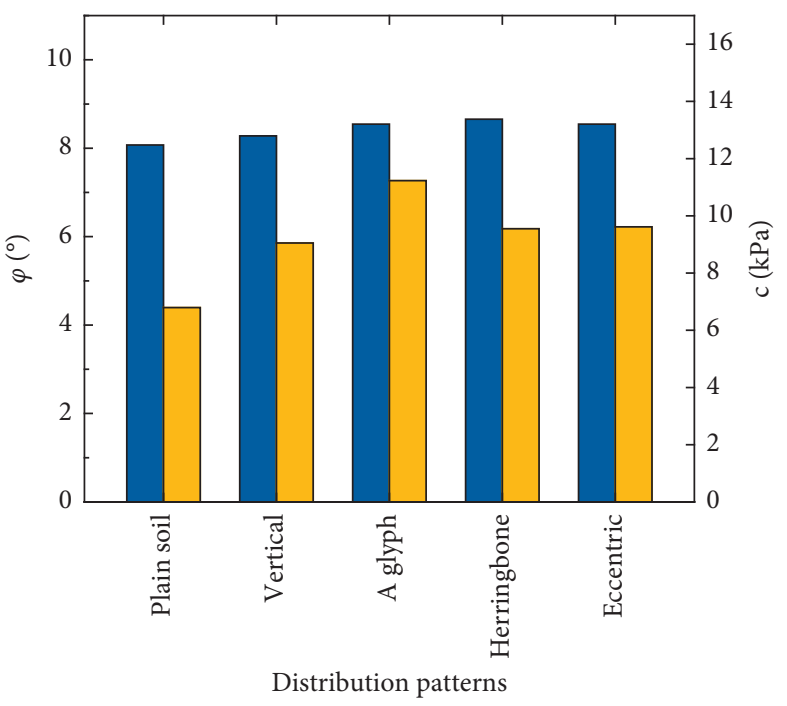

(b)

FIGURE 20: Influence of different root fiber morphological distributions on the (a) shear strength and (b) shear strength index of the rootfibered soil.

bonded to the soil. As a result, the contact area between the root fibers and the soil under common force and coordinated deformation increases. Simultaneously, the "glyph" distribution can fully employ the tensile performance of the root fiber, effectively transferring external force to the surrounding soil through stress diffusion, thereby increasing the shear resistance of the root-fibered soil $[50,51]$.

\section{Conclusions}

In this study, the tensile properties of the carex root fibers were investigated. Secondly, the direct shear test was conducted according to the geotechnical test specifications by remolding the root-fibered soil. The influences of the root fiber content, humidity, moisture content of the test soil, and the distribution form of root fibers on the shear strength of root-fibered soil were analyzed, as well as the contribution of different root fiber morphological distributions to the soil. The final conclusions are as follows:

(1) Considering the root fiber humidity and analyzing shear strength, it was found that the shear strength of the root-fibered soil with low root fiber humidity is greater than that measured with high root fiber humidity. Root fibers can play a significant role in the soil. However, the reinforcing abilities of the root fibers were different. The root fibers with lower humidity had a stronger tensile capacity, and the greater the anchoring effect of the reinforcement was, the higher the shear strength of the root-fibered soil was.

(2) Experiments regarding the influence of soil moisture content on root-fibered soil demonstrated that the higher the soil moisture content was, the lower the cohesion and shear strength were. This is because the smaller the water content, the greater the water film junction force, the significant the coagulation effect, the larger the soil solidity. With the increase of water content, the thickness of water film increases, the bonding effect of water film decreases, the cohesion effect decreases, and the adhesion force decreases. When cohesion weakens to a certain extent, the bonding between particles begins to gradually lose. In addition, the soil showed capillarity effects. When the water molecules in the soil increased, the capillarity effect of the soil relatively weakened, resulting in a decrease in the cohesive and shear strength of the rootfibered soil.

(3) Because the distribution of plant root fibers in soil is more complex, we selected four distributions, namely, "glyph," "herringbone," "eccentric," and "vertical." The results show that the shear strength of carex root-fibered soil with the "glyph" distribution is the highest, while the values for the "herringbone," "eccentric," and "vertical" distributions of other plant root fibers decrease, respectively. The main reason is that the "glyph" root fiber distribution contacts with the soil from multiple angles to form a network structure, which is more closely bonded with the soil. As a result, this distribution increases the contact area of the root and soil under joint stress and deformation and takes full advantage of the tensile strength of the carex root fibers.

\section{Data Availability}

The data used to support the findings of this study are included within the article. 


\section{Conflicts of Interest}

The authors declare that they have no conflicts of interest regarding the publication of this paper.

\section{Acknowledgments}

This research was supported by the LiaoNing Revitalization Talents Program (2005003) for which the authors are grateful.

\section{References}

[1] X. Wang, M.-M. Hong, and Z. Huang, "Biomechanical properties of plant root systems and their ability to stabilize slopes in geohazard-prone regions," Soil and Tillage Research, vol. 189, pp. 148-157, 2019.

[2] D. Boldrin, A. K. Leung, and A. G. Bengough, "Hydro-mechanical reinforcement of contrasting woody species: a fullscale investigation of a field slope," Géotechnique, vol. 19, no. 5, pp. 1-15, 2020.

[3] C. W. W. Ng, "Atmosphere-plant-soil interactions: theories and mechanisms," Chinese Journal of Geotechnical Engineering, vol. 39, no. 1, pp. 1-47, 2017.

[4] L. Giupponi, G. B. Bischetti, and A. Giorgi, "A proposal for assessing the success of soil bioengineering work by analysing vegetation: results of two case studies in the Italian Alps," Landscape and Ecological Engineering, vol. 13, no. 2, 2017.

[5] A. Stokes, P. Chris, B. D. Grant et al., "Ecological mitigation of hillslope instability: ten key issues facing researchers and practitioners," Plant and Soil, vol. 377, no. 1/2, 2014.

[6] R. Forman, D. Sperling, J. A. Bissonette et al., "Road ecology: science and solutions," Ecology, 2003.

[7] R. H. Zhong, X. B. He, Y. H. Bao et al., "Estimation of soil reinforcement by the roots of four post-dam prevailing grass species in the riparian zone of three gorges reservoir, China," Journal of Mountain Science, vol. 13, no. 3, pp. 508-521, 2016.

[8] J. T. Fu, X. S. Hu, and G. Brierley, "The influence of plant root system architectural properties upon the stability of loess hillslopes, Northeast Qinghai, China," Journal of Mountain Science, vol. 13, no. 5, pp. 785-801, 2016.

[9] T. C. Hales and C. F. Miniat, "Soil moisture causes dynamic adjustments to root reinforcement that reduce slope stability," Earth Surface Processes and Landforms, vol. 42, no. 5, 2016.

[10] M. Saifuddin and O. Normaniza, "Rooting characteristics of some tropical plants for slope protection," Journal of Tropical Forest Science, vol. 28, no. 4, pp. 469-478, 2016.

[11] M. Saifuddin and N. Osman, "Evaluation of hydro-mechanical properties and root architecture of plants for soil reinforcement," Current Science, vol. 107, no. 5, 2014.

[12] G. Veylon, M. Ghestem, A. Stokes, and A. Bernard, "Quantification of mechanical and hydric components of soil reinforcement by plant roots," Canadian Geotechnical Journal, vol. 52, no. 11, pp. 1839-1849, 2015.

[13] A. K. Leung, A. Garg, and C. W. W. Ng, "Effects of plant roots on soil-water retention and induced suction in vegetated soil," Engineering Geology, vol. 193, pp. 183-197, 2015.

[14] M. Saifuddin and N. Osman, "Evaluation of hydro-mechanical properties and root architecture of plants for soil reinforcement," Current Science, vol. 107, no. 5, pp. 845-852, 2014.

[15] C. B. Zhang, L. H. Chen, Y. P. Liu, X. D. Ji, and X. P. Liu, "Triaxial compression test of soil-root composites to evaluate influence of roots on soil shear strength," Ecological Engineering, vol. 36, no. 1, pp. 19-26, 2010.

[16] S. B. Mickovski, A. Stokes, R. V. Beek, M. Ghestem, and T. Fourcaud, "Simulation of direct shear tests on rooted and non-rooted soil using finite element analysis," Ecological Engineering, vol. 37, no. 10, pp. 1523-1532, 2011.

[17] Z. Mao, F. Bourrier, A. Stokes, and T. Fourcaud, "Threedimensional modelling of slope stability in heterogeneous montane forest ecosystems," Ecological Modelling, vol. 273, no. 2, pp. 11-22, 2014.

[18] Z. L. Quan, F. Bo, H. B. Cai et al., "Mechanism of riverbank protection by desert riparian vegetation roots in Tarim River basin[J]," Chinese Journal of Rock Mechanics and Engineering, vol. 37, no. 5, pp. 1290-1300, 2018.

[19] S. Bordoloi, J. Ni, and C. Wang, W. Ng, Soil desiccation cracking and its characterization in vegetated soil: a perspective review," Science of the Total Environment, vol. 729, 2020.

[20] C. C. Fan and C. F. Su, "Role of roots in the shear strength of root-reinforced soils with high moisture content," Elsevier, vol. 33, no. 2, 2008 .

[21] A. Stokes, G. B. Douglas, T. Fourcaud et al., "Ecological mitigation of hillslope instability: ten key issues facing researchers and practitioners," Plant and Soil, vol. 377, no. 1-2, pp. 1-23, 2014.

[22] C. W. W. Ng, C. Shi, A. Gunawan, L. Laloui, and H. L. Liu, "Centrifuge modelling of heating effects on energy pile performance in saturated sand," Canadian Geotechnical Journal, vol. 52, no. 8, pp. 1045-1057, 2015.

[23] M. Ghestem, K. Cao, and W. Ma, "A framework for identifying plant species to Be used as 'Ecological Engineers' for fixing soil on unstable slopes," PLoS One, vol. 9, no. 8, 2014a.

[24] M. Saifuddin, N. Osman, M. R. Motior, and A. N. Boyce, "Soil reinforcement capability of two legume species from plant morphological traits and mechanical properties," Current Science, vol. 108, no. 7, pp. 1340-1347, 2015.

[25] A. Jotisankasa and D. Taworn, "Direct shear testing of clayey sand reinforced with live stake," Geotechnical Testing Journal, vol. 39, no. 4, pp. 608-623, 2016.

[26] C. Zhang, X. Zhou, J. Jiang, Y. Wei, J. Ma, and P. D. Hallett, "Root moisture content influence on root tensile tests of herbaceous plants," Catena, vol. 172, pp. 140-147, 2019.

[27] D. Boldrin, A. K. Leung, and A. G. Bengough, "Root biomechanical properties during establishment of woody perennials[J]," Ecological Engineering, vol. 109, 2017.

[28] C. Mattia, G. B. Bischetti, and F. Gentile, "Biotechnical Characteristics of Root Systems of Typical Medit erranean Species [ J]," Plant and Soil, vol. 278, no. 12 2, Article ID 23232, 2005.

[29] B. Li, H. Zhu, B. Xie, L. Luo, G. Li, and X. Hu, "Study on tensile properties of plant root soil complex of alpine meadow in riparian zone of the source area of the Yellow River," Journal of rock mechanics and engineering, vol. 39, no. 02, pp. 424-432, 2020.

[30] C. C. Fan and Y. W. Chen, "The effect of root architecture on the shearing resistance of root-permeated soils," Ecological Engineering, vol. 36, no. 6, pp. 813-826, 2010.

[31] A. K. Leung, D. Boldrin, A. A. Karimzadeh, and A. G. Bengough, "Role of hydromechanical properties of plant roots in unsaturated soil shear strength," Japanese Geotechnical Society Special Publication, vol. 7, no. 2, 2019.

[32] G. Veylon, L. H. Luu, and S. Mercklé, "A simplified method for estimating Newmark displacements of mountain reservoirs[J]," Soil Dynamics and Earthquake Engineering, vol. 100, 2017. 
[33] GBT50123-2019, Standard for soil test method, CHN, Peking, 2019.

[34] L. O. Hollis and R. E. Turner, "The tensile root strength of five emergent coastal macrophytes," Aquatic Botany, vol. 146, 2018.

[35] M. Z. S. Solá, N. Lovaisa, J. S. D. Costa, C. S. Benimeli, M. A. Polti, and A. Alvarez, "Multi-resistant plant growthpromoting actinobacteria and plant root exudates influence $\mathrm{Cr}(\mathrm{VI})$ and lindane dissipation," Chemosphere, vol. 222, 2019.

[36] C. Zhang, X. Zhou, J. Jiang, W. Yang, J. Ma, and D. Paul, "Hallett. Root moisture content influence on root tensile tests of herbaceous plants," Catena, vol. 172, 2019.

[37] Y. Xue, L. Yue, and S. Li, "Experimental study on the effect of water content on mechanical properties of soil-rock mixture [J]," Journal of Engineering Geology, vol. 23, no. 1, pp. 21-29, 2015, (in Chinese).

[38] H. Jiang, R. Cao, and X. Ma, "Study on shear Strength of high liquid limit clay in yellow plain region considering equilibrium Humidity state of subgrade," Chinese Journal of Rock Mechanics and Engineering, vol. 37, no. 12, pp. 2819-2828, 2018.

[39] R. L. Hathaway and D. Penny, "Root strength in SomePopulusandSalixClones," New Zealand Journal of Botany, vol. 13, no. 3, pp. 333-344, 1975.

[40] H. F. Jin, D. M. Shi, X. Y. Zeng, S. S. Wang, T. Duan, and Y. B. Lou, "Mechanisms of root-soil reinforcement in bioembankments of sloping farmland in the purple hilly area, China," Journal of Mountain Science, vol. 16, no. 10, pp. 2285-2298, 2019.

[41] D. Boldrin, A. K. Leung, and A. G. Bengough, "Root biomechanical properties during establishment of woody perennials[J]," Ecological Engineering, vol. 109, 2017.

[42] J. J. Ni, A. K. Leung, and C. W. W. Ng, "Influences of plant spacing on root tensile strength of Schefflera arboricola and soil shear strength," Springer Japan, vol. 15, no. 2, 2019.

[43] D. Boldrin, A. K. Leung, and A. G. Bengough, "Effects of root dehydration on biomechanical properties of woody roots of Ulex europaeus," Plant and Soil, vol. 431, no. 1-2, 2018.

[44] D. Cazzuffi, G. Cardile, and D. Gioffrè, "Geosynthetic engineering and vegetation growth in soil reinforcement applications," Transportation Infrastructure Geotechnology, vol. 1, no. 3-4, pp. 262-300, 2014.

[45] X. Li, J. Li, X. Yuan, and Y. Wang, "Application of quasi cohesive principle of reinforced soil in upper limit analysis method," in Proceedings of the second National Symposium on environmental geotechnical engineering and geosynthetics, pp. 286-290, Mexico, USA, October 2008.

[46] Z. H. Ming and LP. Xiao, "Application of aqueous film theory to study of unsaturated soil's suction," Rock and Soil Mechanics, vol. 28, no. 7, pp. 1323-1327, 2007.

[47] Z. Han, J. Li, P. Gao, B. Huang, J. Ni, and C. Wei, "Determining the shear strength and permeability of soils for engineering of new paddy field construction in a hilly mountainous region of southwestern China," International Journal of Environmental Research and Public Health, vol. 17, no. $5,2020$.

[48] X. Xu, J. Wenbin, and K. Liu, "Influence of water content and dry density on shear strength parameters of residual soil," Underground Space and Engineering, vol. 11, no. 02, pp. 364-369, 2015.

[49] Z. Lu, "Explorations on the suctional shear strength of saturated soils," China Railway Science, vol. 20, no. 2, Article ID 1661102, 1999.
[50] B. Lian, J. Peng, H. Zhan, and X. Wang, "Mechanical response of root-reinforced loess with various water contents," Soil \& Tillage Research, vol. 193, 2019.

[51] D. Zhang, J. Cheng, and Y. Liu, "Spatio-temporal dynamic architecture of living brush mattress: root system and soil shear strength in riverbanks," Forests, vol. 9, no. 8, 2018. 